DIW BERLIN

Discussion

Papers

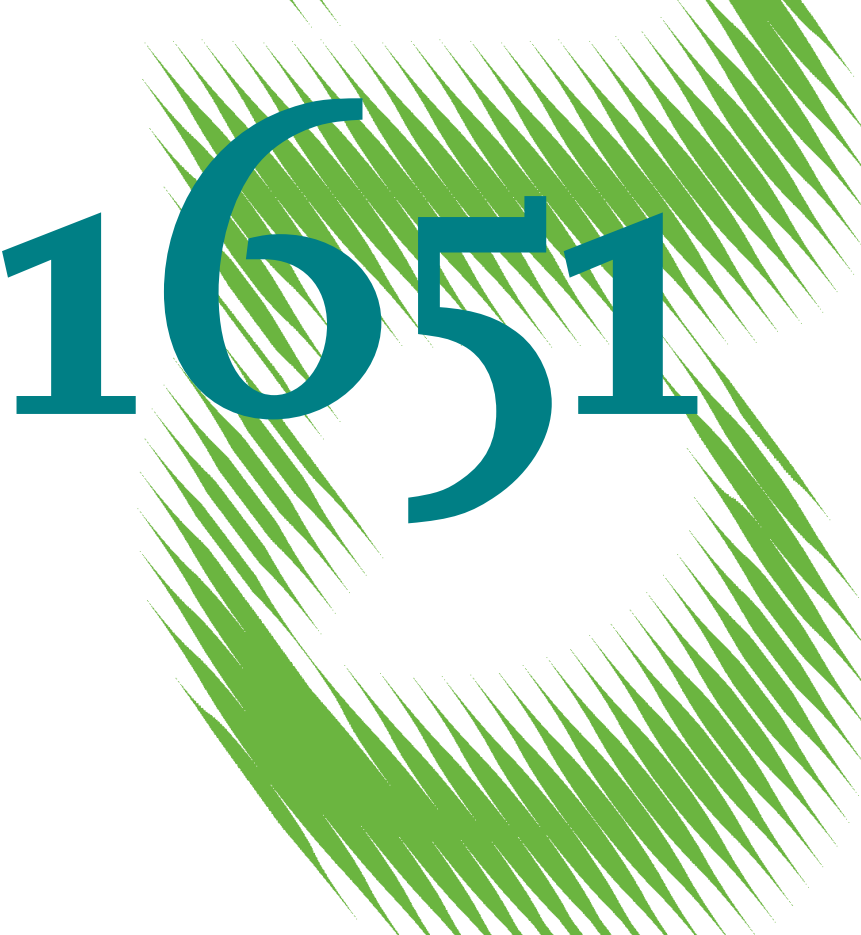

Paid Parental Leave and Child Development: Evidence from the 2007 German Parental Benefit Reform and Administrative Data 
Opinions expressed in this paper are those of the author(s) and do not necessarily reflect views of the institute.

IMPRESSUM

(C) DIW Berlin, 2017

DIW Berlin

German Institute for Economic Research

Mohrenstr. 58

10117 Berlin

Tel. +49 (30) $89789-0$

Fax +49 (30) $89789-200$

http://www.diw.de

ISSN electronic edition 1619-4535

Papers can be downloaded free of charge from the DIW Berlin website:

http://www.diw.de/discussionpapers

Discussion Papers of DIW Berlin are indexed in RePEc and SSRN:

http://ideas.repec.org/s/diw/diwwpp.html

http://www.ssrn.com/link/DIW-Berlin-German-Inst-Econ-Res.html 


\title{
Paid parental leave and child development: Evidence from the 2007 German parental benefit reform and administrative data
}

\author{
Mathias Huebener, ${ }^{1,3 *}$ Daniel Kuehnle, ${ }^{2}$ C. Katharina Spiess ${ }^{1,3}$ \\ ${ }^{1}$ DIW Berlin, ${ }^{2}$ Friedrich-Alexander University of Erlangen-Nuremberg, ${ }^{3}$ Freie Universität Berlin \\ *Corresponding author: mhuebener@diw.de
}

March 2017

\begin{abstract}
This paper examines the effects of a substantial change in publicly funded paid parental leave in Germany on child development and socio-economic development gaps. For children born before January 1, 2007, parental leave benefits were means-tested and paid for up to 24 months after childbirth. For children born thereafter, parental leave benefits were earnings-related and only paid for up to 14 months. Higher-income households benefited more from the reform than low-income households. We study the reform effects on children's language skills, motor skills, socio-emotional stability, and school readiness using administrative data from mandatory school entrance examinations at age six and a difference-in-differences design. We find no impact of the reform on child development and socio-economic development gaps. The effects are precisely estimated and robust to various model specifications and sample definitions. Our results suggest that such substantial changes in parental leave benefits are unlikely to impact children's development. These findings are consistent with recent studies showing that temporary unrestricted transfers and maternal part-time employment have a limited impact on parental investments in their children.
\end{abstract}

Keywords: Parental leave benefit, child development, skill formation, parental investments, school readiness, motor skills, language skills, socio-emotional stability, socio-economic differences

JEL: J13, J18, J22, J24 


\section{Introduction}

Over the past 15 years, a growing body of evidence has shown that early childhood conditions can have long-lasting effects on children's educational attainment, labour market outcomes, and adult health (e.g. Cunha et al., 2006; Almond and Currie, 2011; Heckman and Mosso, 2014). These early conditions differ considerably by children's socio-economic status (SES), contributing to the emergence of SES gaps in child development very early in life (e.g. Todd and Wolpin, 2007). Bradbury et al. (2015), for instance, show for the US, the UK, Australia, and Canada that SES gaps in child development are already pronounced at age 5 and increase further throughout the first years of schooling. Consequently, many children from low-SES backgrounds fall behind. ${ }^{1}$

To what extent do public policies affect the link between family background and child development? One of the most important policy tools across OECD countries to support families around childbirth are parental leave policies. The length of leave offered by these policies has substantially increased since the 1970s (OECD, 2016d). These policies affect several conditions in early childhood (see, e.g. Björklund and Salvanes, 2011) and, thus, may impact child development. In particular, these expansions in parental leave policies reduce maternal labour supply after childbirth (e.g. Ondrich et al., 1996; Lalive and Zweimüller, 2009; Schönberg and Ludsteck, 2014), affecting the time parents can spend with their children. This parental time may be an important input for the development of children (e.g. Hsin and Felfe, 2014; Fiorini and Keane, 2014; Del Bono et al., 2016). Moreover, parental leave benefits directly impact household income, which determines the resources and goods parents can invest into the development of their children (e.g. Dahl and Lochner, 2012; Løken et al., 2012). ${ }^{2}$

\footnotetext{
${ }^{1}$ Other examples documenting considerable differences in children's skills at school entry include Feinstein (2003), Cunha et al. (2006) and Cunha and Heckman (2007).

${ }^{2}$ The various channels through which parental leave policies may impact child development are carefully described in, e.g., Björklund and Salvanes (2011), Dustmann and Schönberg (2011) and Danzer and Lavy
} 
Despite the substantial impact that leave policies have on family resources, we know little about the effect of such policies on early child development and even less on SES development gaps: Previous studies almost exclusively focus on expansions in parental leave entitlements from the 1970s through 1990s. Since then, many factors related to child development have changed substantially across countries, such as maternal labour force participation, day care availability, and social norms. Therefore, it is unclear whether the findings from earlier parental leave expansions are still valid. Furthermore, very little is known about whether these policies impact high- or low-SES families differently, and whether they affect SES development gaps.

Our paper addresses these questions by examining the effects of the 2007 German paid parental leave reform on child development. The reform substantially changed the eligibility criteria and benefit payments: For children born before January 1, 2007, parental leave benefits were means-tested and paid for up to two years after childbirth for eligible mothers. For children born thereafter, parental leave benefits were earnings-related and paid for up to 14 months in total per couple. The reform expanded the proportion of eligible mothers from $77 \%$ to almost $100 \%$. The additional public benefit payments of the programme amounted to about $0.1 \%$ of GDP in the first year after implementation. ${ }^{3}$ Previous studies document that the reform strongly affected parental labour supply (e.g., Bergemann and Riphahn, 2015; Geyer et al., 2015), household income (Wrohlich et al., 2012), breastfeeding duration (Kottwitz et al., 2016), and higher-order fertility (Cygan-Rehm, 2016). ${ }^{4}$ Despite these changes in parental behaviour and resources, we still do not know whether the reform also affected child development. As the reform favoured high-SES households more in terms of parental leave benefit payments and duration than low-SES households,

(2016).

${ }^{3}$ Own calculations based on Federal Ministry of Finance (2007), German Federal Statistical Office (2008), and German Federal Statistical Office (2016).

${ }^{4}$ Huebener et al. (2016) summarise the literature on the 2007 German paid parental leave reform. 
the reform had the potential to widen the socio-economic gap in child development. We estimate the causal effects on child development with a difference-in-differences approach that compares children born before and after the reform cut-off date. As our control group, we use children born in nearby years around the same cut-off date.

Our study makes the following contributions to the literature. First, while the previous literature exclusively studied introductions or expansions of parental leave, we analyse a recent reform that both expanded eligibility for paid leave in the first year after childbirth and removed paid leave in the second year after childbirth. By changing means-tested benefits to earnings-related benefits, high-SES households benefited more from the reform than low-SES households in terms of parental leave eligibility and benefit payments. Thus, the German reform sheds new light on whether parental leave policies affect children from low- and high-SES families differently, thereby impacting SES development gaps. Second, we provide new evidence of parental leave policies on children's short-run outcomes. Most existing studies focus on children's long-run outcomes and find mostly small or no reform effects. However, to design appropriate policies, it is crucial for policymakers to know whether parental leave policies have any effects on children in the short-run, or whether initial effects fade-out over time. Third, we examine several important dimensions of child development assessed by public health paediatricians during school entrance examinations at age six. Our analyses build on an exceptionally rich, administrative data source of child development covering the full population of children from one German state. Previous studies on short-run effects are either constrained by child outcomes conveying limited information on child development (e.g. birth weight, infant mortality, premature birth, and hospitalisations) or by sample sizes requiring more restrictive assumption for the identification of causal effects (see Section 2).

Our results show that this substantial change in parental leave benefit regulations had no impact on children's language skills, motor skills, socio-emotional stability, and school 
readiness at age six. The point estimates from our large sample are close to zero and precisely estimated. When we stratify the sample by parents' education, we estimate again very small and insignificant treatment effects on child development. Consequently, we find no evidence for changes in the SES development gap, despite the reform favouring high-SES families over low-SES families.

To explain our zero-reform effects, we draw on findings from recent economic studies on the determinants of child development. Households gaining eligibility for (higher) parental leave benefits receive temporary, unrestricted transfers. Such transfers are unlikely to have a significant impact on parents' productive investments into their children (Carneiro and Ginja, 2016) and on child development (Heckman and Mosso, 2014; Del Boca et al., 2016). Moreover, maternal labour supply mostly reacted to the reform after the first six months following childbirth, and typically involved part-time employment. The literature suggests that maternal part-time employment beyond the first six months after childbirth has, at most, a small impact on child development, especially when alternative care arrangements are of comparable quality to maternal care (see, e.g. Brooks-Gunn et al., 2010; Bernal and Keane, 2010). One important explanation for the small impact of maternal part-time employment on child development is the limited effect of maternal employment on relevant parental investments in their children (e.g. Hsin and Felfe, 2014; Del Bono et al., 2016).

The remainder of the paper is organised as follows. Section 2 summarises the previous literature on parental leave policies and child development. Section 3 provides information about the institutional background and emphasises the heterogeneous effects of the 2007 parental leave reform. Section 4 introduces the data and provides descriptive statistics. Section 5 outlines our empirical strategy. We present the main results and a large set of robustness checks in Section 6. We discuss our findings in Section 7 and conclude in Section 8 . 


\section{State of the literature}

A small economic literature studies the causal effects of parental leave policies on child outcomes exploiting individual-level data and introductions or expansions of parental leave entitlements for effect identification. ${ }^{5}$ Figure 1 summarises this literature by highlighting the country and year of reform, the timing and intensity of the change in paid or unpaid parental leave expansion, the age at which child outcomes are measured, and the main results. ${ }^{6}$ For changes in parental leave mandates in the first year after childbirth, only studies examining the introduction of parental leave (i.e. changes at the extensive margin) find effects on child development. For the US, Rossin (2011) analyses the introduction of 12 weeks of unpaid parental leave and finds evidence for small improvements in birth weight and reductions in infant mortality rates for children of highly educated mothers, but largely no effects for children of less-educated and single mothers. For Norway, Carneiro et al. (2015) examine the introduction of four months of paid parental leave in 1977 and find a decline in high school drop-out rates (for children from low-educated mothers) and an increase in wages.

Studies that examine paid parental leave expansions within the first year after childbirth (i.e. changes at the intensive margin) in four different countries cannot find effects on child outcomes (Dustmann and Schönberg, 2011; Würtz Rasmussen, 2010; Dahl et al., 2016; Beuchert et al., 2016; Baker and Milligan, 2008, 2010, 2015). Across these studies, the timing and intensity of the expansion, and the social and institutional contexts (such as female labour force participation rates, the availability of day care, and social norms) vary. But even within a similar institutional context, such as in Norway, Dahl et al. (2016) do not find any effects on child outcomes of further paid parental leave expansions from 18 to

\footnotetext{
${ }^{5}$ Early studies on the topic examine variations in parental leave policies across countries in aggregated data (Ruhm, 2000; Tanaka, 2005).

${ }^{6}$ For a detailed description of the previous literature of parental leave policies on child development, see, e.g. Danzer and Lavy (2016) and Huebener (2016).
} 
35 weeks after childbirth, while Carneiro et al. (2015) identify effects of the introduction of parental leave. These findings suggest that the timing of parental leave policies matters, but an insufficient magnitude of the expansions may also explain the results. Furthermore, most child outcomes are measured between the age of 14 and 33, so it is not clear whether initial reform effects faded out over time.

Studies that analyse expansions of paid and unpaid parental leave time in the second year after childbirth show some effects on child development measured at age 14 to 16 . These effects mostly occur in subgroups. For instance, Liu and Skans (2010) examine the extension of paid parental leave from 12 to 15 months in Sweden. They find a modest improvement in grade point averages for daughters of highly educated mothers. Dustmann and Schönberg (2011) also evaluate one expansion in unpaid parental leave from 18 to 36 months in Germany in 1992, and find a very small, negative effect on children's school track choice. Danzer and Lavy (2016) analyse the effects of an Austrian expansion of paid parental leave from 12 to 24 months. The study finds positive reform effects on test scores at age 15 for sons of highly educated mothers, but negative effects for sons of loweducated mothers. They argue that the alternative mode of child care may be important in explaining the heterogeneous effects.

Few studies focus on the short-run effects of parental leave reforms on child outcomes. Beuchert et al. (2016) study a paid parental leave expansion from 6 to 11 months in Denmark and find no effects on childrens' hospital visits in the first three years after childbirth. Rossin (2011) also analyses child health outcomes (i.e. birth weight, infant mortality, premature birth). Both studies are uninformative about the effects on several other dimensions of child development, including cognitive and non-cognitive outcomes. The only other studies that examine parental leave effects on richer early child development outcomes evaluate a Canadian parental leave expansion from 6 to 12 months. Baker and Milligan $(2008,2010,2015)$ mostly find no effects of the reform on health and development 
outcomes up to age 3, or on measures of children's cognitive and non-cognitive development at ages 4 through 5 . While the outcome measures are very rich, the limited sample size and the sampling procedure of the survey data require estimating causal reform effects through cohort comparisons in an eight-year window around the reform. This approach may be more sensitive to other confounding effects (such as cohort and age-at-test effects) than approaches that compare child outcomes in the close neighbourhood of reform eligibility cut-offs. In a discussion paper, Huber (2015) also analyses the effects of the 2007 German reform on child outcomes at ages 0 through 3 . In contrast to our study, the analysis is based on parent-reported measures for child development and a comparably small sample from the German Socio-Economic Panel Study (SOEP). The point estimates are very large compared to previous findings in the literature, unstable across specifications and imprecisely estimated, preventing a clear conclusion.

\section{Background}

\subsection{The 2007 German paid parental leave reform}

To set the stage, we first provide some information on the institutional background in which the parental leave reform was implemented. In 2006, the maternal labour force participation rate of women aged 25-54 with at least one child aged 0-14 was 63\% in Germany (OECD average 66.1\%), the fertility rate was 1.33 children per woman (OECD average 1.69), and the day care participation rate for 0-2 year olds, including centre-based and family day care services, was $13.6 \%$ (OECD average 30\%). ${ }^{7}$ Mothers were generally not allowed to work during the six weeks before and, without exception, the eight weeks after childbirth. Mothers who were employed prior to giving birth received a full wage

\footnotetext{
${ }^{7}$ Statistics are taken from OECD (2016a,b,c). There exist differences between East and West Germany. Throughout the last decades, West Germany has had lower female labour force participation rates and lower day care attendance for children below the age of two than East Germany (see, e.g. Haan and Wrohlich, 2011; Schober and Spiess, 2013; Schnabel, 2016).
} 
replacement during this mother protection period. Moreover, parents taking leave had the right to return to their job within 36 months after childbirth.

Parents of children born before January 1, 2007, were eligible for child-rearing benefits (Erziehungsgeld). These publicly funded benefits were means-tested and families were eligible if their yearly net income was below a certain threshold, which varied with the household structure (couples/singles), number of children, and time since giving birth (Bundeserziehungsgeldgesetz). Once the net income exceeded the threshold, benefit amounts were reduced. In Table 1, we provide descriptive statistics on parental leave eligibility based on representative household data from the German Socio-Economic Panel Study (SOEP, Wagner et al., 2007). Overall, 77\% of parents were eligible for 300 Euros of monthly benefits (corresponding to about $11 \%$ of pre-birth net household income, see Table 1) for up to six months after childbirth. Due to repeated means-testing after 6 and 12 months, and lower household income eligibility thresholds, the share of eligible parents falls to $47 \%$ for 7 to 12 months after childbirth, and to $40 \%$ for benefits 12 to 24 months after childbirth. Part-time work of up to 30 hours per week was permitted in the benefit payment period. ${ }^{8}$ In 2006, the German government substantially reformed the paid parental leave regulations pursuing five main policy objectives (Bujard, 2013). First, the new benefit (Elterngeld) aimed to safeguard family income during the first year after childbirth. Second, the reform intended to increase parental care time during the first year after childbirth. Third, the reform aimed at increasing mothers' economic independence by increasing the financial incentives for an earlier return to work during the second year after childbirth. Fourth, the reform sought to increase paternal involvement in child rearing. Fifth, the reform intended to increase fertility. While fertility was not originally targeted by the reform, it was a recurring topic in the public debate and eventually interpreted as a policy objective. The

\footnotetext{
${ }^{8}$ Parents eligible for benefits for up to 24 months could also choose higher benefits (450 Euros) for a period of up to 12 months. For children born in 2005 and 2006, only $10 \%$ of all parents chose this option (own calculations based on SOEPv30).
} 
reform did not explicitely target child development.

The law concerning the paid parental leave reform was passed in September 2006 and affected parents of children born on or after January 1, 2007 (Bundeselterngeld- und Elternzeitgesetz). Instead of being means-tested, the new benefit depends on the average net labour income earned in the 12 months prior to giving birth. Parents taking paid parental leave receive monthly benefits equalling $67 \%$ of their average monthly pre-birth net earnings; the benefit is capped at 1,800 Euros per month. As before, low-income parents, or those who did not work prior to giving birth, still receive 300 Euros per month. In addition to the changed eligibility criteria and benefit amounts, the transfer period was reduced from 24 to 12 months. Two additional months were granted for single parents and if both partners take parental leave for at least two months. ${ }^{9}$ The reform did not change the 36-month job protection period, the maternal protection period around childbirth, or part-time employment regulations during the benefit payment period. ${ }^{10}$

The take-up rate of the new paid parental leave benefits is $96.3 \%$ of all parents (German Federal Statistical Office, 2008), with average benefits amounting to 634 Euros per month for mothers and 1061 Euros for fathers (see Table 1).

\subsection{Heterogenous effects of the paid parental leave reform}

Overall, families were affected differently by the reform, depending on parents' pre-birth earnings and household income (see Table 2). First, consider high-earning mothers and high-income households that were not eligible for paid parental leave benefits prior to

\footnotetext{
${ }^{9}$ The maximum length of 14 months of paid parental leave could be split flexibly between both parents, with a minimum of two months per parent. Approximately $96 \%$ of parents assign the main benefit period ( $>7$ months) to the mother. In our observation period, $15 \%$ of fathers take paid parental leave, mostly for 2 months. Alternatively, parents can also choose to receive only half of the monthly benefits for a doubled period of time, i.e. for up to two years. Only $8 \%$ of parents choose this option (German Federal Statistical Office, 2008).

${ }^{10}$ After the reform, parents who work part-time receive a benefit that amounts to $67 \%$ of the difference between pre- and post-birth earnings.
} 
the reform (or for only 6 months); after the reform, these mothers were newly eligible for 12 months of paid parental leave. In the first 12 months following childbirth, nothing changes for these households. Second, consider mothers with low pre-birth earnings and low household income; these mothers were eligible for two years of paid parental leave before the reform. After the reform, they still receive the minimum benefits of 300 Euros per month in the first year, but they lose eligibility for benefits in the second year after childbirth. Finally, households between these two groups were previously eligible for benefits of 300 Euros per month for up to 24 months, but now receive higher benefit payments only during the first year after childbirth. The likelihood for households to receive higher overall benefits increases with their pre-birth earnings.

Consequently, the reform benefited high-SES families more than low-SES families in terms of eligibility expansions and benefit payments. On average, higher-educated mothers benefited more from the parental leave reform, as they typically come from higher-income households as well as because they have higher pre-birth employment rates and earnings. To illustrate this, columns 2 and 3 of Table 1 summarise the benefit amounts and durations by mothers' levels of education. On average, highly educated mothers (i.e. with uppersecondary school certificates) were less likely than low- and medium-educated mothers (i.e. with lower- and middle-secondary school certificates) to receive parental leave benefits before the reform. ${ }^{11}$ While only $40 \%$ of the highly educated mothers received parental leave benefits for more than six months, $53 \%$ of low- and medium-educated mothers did. For the second year after childbirth, only $33 \%$ of highly educated mothers and $45 \%$ of low- and medium-educated mothers received benefits.

After the reform, almost all mothers were eligible for parental leave benefits. Highly educated mothers receive, on average, 771 Euros per months, while lower educated mothers

\footnotetext{
${ }^{11}$ In our main data set on child outcomes, we observe parents' highest secondary school certificate. For consistency, we use the same definition of low-/medium- and highly educated mothers in the SOEP data.
} 
receive, on average, 563 Euros per month. In addition, twice as many fathers take (higherpaid) parental leave among the group of highly educated mothers, which further increases the total benefit duration by up to two months.

Several previous studies provide evidence for the reform's heterogeneous effects on various outcomes. They show that the reform reduced the labour supply of mothers in the first year after birth (especially in high-income households), and increased their labour supply in the second year after birth (especially in low-income households, see Wrohlich et al., 2012; Kluve and Tamm, 2013; Kluve and Schmitz, 2014; Bergemann and Riphahn, 2015; Geyer et al., 2015). The changes in maternal employment mostly occur at the margin of parttime work. With respect to household income in the first year after childbirth, the reform had a stronger impact on households where the mother holds a tertiary education degree (Wrohlich et al., 2012). These changes are consistent with the heterogeneous incentive structure of the reform. Moreover, the reduction in high-earning mothers' labour supply in the first year after childbirth is also consistent with an increase in their breastfeeding durations (Kottwitz et al., 2016). In addition, Cygan-Rehm (2016) analyses the reform's effects on higher-order fertility and finds a lower probability of having another child within 21 and 45 months after the previous birth for low-income mothers. High-income mothers increase their birth spacing, but do not show significant changes on higher-order births 45 months after previous births.

Given these heterogeneous effects, how then would we expect the reform to affect child development, and the SES development gap? First, with respect to income changes, highly educated mothers experience a stronger increase in benefit payments and household income, which may causally improve children's outcomes (Dahl and Lochner, 2012; Løken et al., 2012). ${ }^{12}$ At the same time, the recent literature suggests that parental child invest-

\footnotetext{
${ }^{12}$ Moreover, there might be a negative income effect for highly educated mothers, as the amount of the benefit does not substitute the entire income. This effect is supposed to be of minor importance for middleand higher-income mothers as the majority of mothers were also taking unpaid leave in the first year after
} 
ments hardly react to transitory income shocks compared to changes in permanent income (Carneiro and Ginja, 2016) and that unrestricted transfers have little impact on child development (Heckman and Mosso, 2014; Del Boca et al., 2016). Given that the reformed parental leave benefit can be interpreted as a transitory income shock or as an unrestricted transfer, the income effect of the reform on child development is ambiguous.

Second, how do we expect changes in maternal labour supply to affect child development? The reform led highly educated mothers to reduce their labour supply in the first year after childbirth and less-educated mothers to increase their labour supply in the second year after childbirth. Highly educated mothers may, therefore, spend more time with their children in the first year after childbirth after the reform. Increases in maternal care time may positively affect children's outcomes through a stronger mother-child attachment (e.g. Berger et al., 2005), longer breastfeeding durations (e.g. Borra et al., 2012), and more interactions between mother and child (Del Bono et al., 2016). However, the effect of maternal time on child development depends on the activities parents perform with their children (Del Bono et al., 2016). ${ }^{13}$ For instance, educational activities benefit child development more than recreational activities and are more frequently provided by higher-SES parents (see, e.g. Kalil et al., 2012; Gimenez-Nadal and Molina, 2013, and for Germany, see, e.g. Autorengruppe Bildungsberichterstattung, 2016). As the reform increased maternal time in the first year after childbirth more strongly for high-SES households, the reform may widen the already existing SES gaps in child development. Still, it remains unclear whether the parental leave reform led to changes in interactions between parents and children relevant for child development (Carneiro and Ginja, 2016).

Furthermore, potential effects of maternal labour supply on child development depend on

childbirth for a certain period of time, which is now partly compensated.

${ }^{13}$ Other recent contributions on the strong positive relationship between maternal time inputs and children's development include Todd and Wolpin (2007), Fiorini and Keane (2014) and Del Boca et al. (2016). For an early study on this, see, e.g. Leibowitz (1977). 
the timing of returning to work, on hours worked, and on the quality of the alternative care mode (e.g. Brooks-Gunn et al., 2010). In our setting, the availability of publicly funded day care for children under the age of three is very low and the main alternative to parental care is usually informal care provided by grandparents or other family members (Hank and Buber, 2009). The reform changed maternal (mostly part-time) labour supply mainly after the first six months after childbirth. These margins, i.e. part-time employment occuring beyond the first six months after childbirth, with alternative care arrangements of comparable quality, have very small effects on child development (e.g. Bernal and Keane, $2010) \cdot{ }^{14}$

Overall, the net reform effect on child development depends on whether parents effectively change their investments (time and goods) in their children, and whether marginal returns to additional child investments are meaningful for child development. We next describe the data that we use to answer this empirical question.

\section{Data}

\subsection{School entrance examinations}

We use administrative data from school entrance examinations covering the full population of one German federal state, Schleswig-Holstein. ${ }^{15}$ Before entering primary school at the age of six, every child in Germany is medically screened by a public health paediatrician. The paediatrician examines children's development with respect to numerous development

\footnotetext{
${ }^{14}$ Small reform effects on higher-order births of low-income mothers (Cygan-Rehm, 2016) could also suggest a child-quality/-quantity trade-off (Becker and Lewis, 1974). However, Angrist et al. (2010) find no causal effect for such a trade-off, so that we deem a slightly smaller number of siblings in our setting (which is not supported by our data) not to be an important explanation for our findings.

${ }^{15}$ Schleswig-Holstein covers $3.6 \%$ of the German population. We examine Schleswig-Holstein due to restricted data access in the other federal states. To assess the external validity of our analysis, Table A.1 compares the demographic and socio-economic characteristics of the population of Schleswig-Holstein to the population in other federal states in West Germany. Schleswig-Holstein is very close to other West German averages, apart from migration background and the degree of urbanisation.
} 
indicators. Taking into account the results from several tests, the paediatrician ultimately provides an assessment of the child's school readiness, i.e. whether the child's school start should be accompanied by further supportive developmental measures.

The administrative records we use cover all children from three cohorts entering school between 2012-2014. A school entrance cohort includes children born between July of the previous year, and June of the year of school entry. The school entrance examinations are conducted in the six months before school entry. Typically, older children are called in first to the examination, younger children afterwards. The data includes detailed information about children's health and development, and some information about family characteristics, such as parental schooling, migration background, and living arrangements. This information is reported voluntarily by the accompanying parent (typically the mother). ${ }^{16}$

In our analysis, we focus on four dimensions of child development: children's language skills, motor skills, socio-emotional stability, and an overall assessment of their school readiness. These outcomes are important predictors of later educational attainment (see, e.g. Duncan et al., 2007; Grissmer et al., 2010), later health outcomes and labour market performance (e.g. Cunha et al., 2006; Blanden et al., 2007; Carneiro et al., 2007).

Paediatricians examine children's language development with respect to their ability to use prepositions, build plural words, and repeat pseudo-words. Children receive a score that determines whether or not their language development lags behind. To assess motor skill development, children need to jump on one leg, stand on one leg, and jump over a line as many times as possible within 10 seconds. If they do not manage to meet specific thresholds, they are classified as having motor skill deficiencies. Socio-emotional development is clinically assessed by the paediatrician: children are classified as having socio-emotional problems if they receive medical or psychological treatment, or if the paediatrician di-

\footnotetext{
${ }^{16}$ The data does not contain information about parental employment or income.
} 
agnoses that further treatment is necessary. ${ }^{17}$ In the data, we observe the paediatrician's assessment of children's developmental deficiencies in their language skills, motor skills and socio-emotional stability as a binary indicator. ${ }^{18}$ We reverse the scales such that higher outcomes are associated with better skills.

Children's overall school readiness is assessed by the paediatrician taking into account the examination results and other (to the econometrician) unobserved factors related to children's development. It is also recorded in the data as a binary variable. A negative school readiness assessment indicates the need of the child for additional supportive development measures. It does not defer children's school entry. All children turning six before June 30 need to enter school in the same year. Delayed school entries are granted only exceptionally based on adverse health conditions of the child. For the school entry cohort 2013, about $1 \%$ of children were delayed.

\subsection{Descriptive statistics}

Our sample consists of 44,997 children. ${ }^{19}$ Descriptive statistics of the full sample and the subsamples stratified by mothers' level of education are provided in Table 3. Panel A describes children's developmental outcomes in the school entry examinations. $71.5 \%$ of children reach a sufficient level of language competencies, $81 \%$ are considered stable in their

\footnotetext{
${ }^{17}$ In some counties, paediatricians base their assessment additionally on information from the Strength and Difficulties Questionnaire (SDQ, Goodman et al., 1998). The SDQ assesses children's socio-emotional development with five different subscales: emotional problems, hyperactivity, peer relationships, social behaviour, and behavioural problems. Note that our econometric framework accounts for differences between counties regarding the additional usage of the SDQ through county-examination-year fixed effects.

${ }^{18}$ Some counties also report the specific test results of children on which the paediatricians base their binary assessment of child development. Our findings are not sensitive to the type of variables used in the analyses (see Appendix Table A.2).

${ }^{19}$ We restrict the sample to children for whom we observe the outcomes in all of the four domains of child development. Missing information is unrelated to the 2007 German parental leave reform. We account for different sample compositions of counties across school entry cohorts with examination-year-county fixed effects. Children belonging to Danish minorities living in Schleswig-Holstein are marked in the data, and have been removed from the sample. Our main results remain robust when we include these children in our sample (results are available upon request).
} 
socio-emotional development, $82.5 \%$ show a sufficient level of motor skills development, and $84 \%$ of children are considered ready for school. Columns 2 and 3 in Table 3 reveal considerable SES development gaps as children of highly educated mothers show higher levels of skill development across all domains.

Panel B of Table 3 provides information on child characteristics. Children are on average 72.6 months (6 years) old when they are examined. $48.8 \%$ of children in the sample are girls. The mean birth weight is 3382 grams. At the time of the examination, children have spent on average 3.4 years in day care. $21.2 \%$ of children in our sample have a migration background (i.e. one or both parents are born abroad). Panel $\mathrm{C}$ of Table 3 provides information on children's family background. Mothers have an average of 10.9 years of schooling, fathers have an average of 11.7 years of schooling. ${ }^{20}$ About $79.2 \%$ of children live with both parents and $14.1 \%$ live with one parent. For $85 \%$ of the children in our sample, German is the only language spoken at home, in another $10.7 \%$ it is the main language. On average, 2.2 children live in the household. ${ }^{21}$

In Table 4, we present OLS estimates from multivariate regressions showing that these child and family characteristics strongly correlate with the child development outcomes. The age of the child, birth weight, time spent in day care, and parental years of schooling all correlate positively with children's skill development. Across all measures, girls show higher skill development levels. Children with more siblings and those who are not living with both parents show lower levels of skill development. Children's migration background and the language spoken at home correlate negatively with children's language skills and their school readiness. These relationships are common in the literature (for reviews, see, e.g.

\footnotetext{
${ }^{20}$ Lower-secondary school certificates are typically earned after 9 years of schooling, middle-secondary school certificates after 10 years, and upper-secondary school certificates after 13 years. In the data, we observe the school certificate that parents hold and assign the typical length of schooling.

${ }^{21}$ Table 3 also reports the share of missing information in the covariates. We checked whether missing information is related to the introduction of the reform and cannot find any evidence of a systematic relationship (see Table 5).
} 
Bradley and Corwyn, 2002; Maggi et al., 2010) and validate the relevance of the analysed dimensions of child development.

\section{Empirical strategy}

Our aim is to estimate the intention-to-treat effect (ITT) of the 2007 German paid parental leave (PPL) reform on children's development. The reform applies a sharp eligibility criterion based on children's birth dates, so that we could compare the developmental outcomes of children born shortly before and after the cut-off date. Such a comparison of means yields unbiased estimates of the reform effects if the birth date is as good as randomly assigned around the policy cut-off. However, as one broadens the window of comparison around the cut-off, this approach risks confounding the estimates of the reform effect with seasonal and age-at-examination effects. To eliminate these potential biases, we use children born in the same months but in years not affected by policy changes (both pre- and post-reform) as our control group. Similar to, for example, Dustmann and Schönberg (2011), Carneiro et al. (2015), and Danzer and Lavy (2016), this methodology combines the idea of a regression discontinuity design (to assign the treatment status) with a difference-in-differences design to isolate the reform effect from potential seasonal or age-at-examination effects.

This difference-in-differences framework relies on two main assumptions to produce unbiased estimates of the reform effect. The first assumption requires common trends in seasonal effects and age-at-examination effects of treatment and control cohorts in the absence of the reform. We run several checks that support the plausibility of this assumption (for details, see Section 6.3).

The second assumption is that the reform does not impact the composition of child and family characteristics of children born in specific months. Three potential concerns may violate this assumption. First, strategic manipulations of birth dates could change the sample composition. The new parental leave law passed parliament in September 2006 
and applied to all children born on or after January 1, 2007. Mothers giving birth in the neighbourhood of the cut-off date had already conceived when the law was passed. Still, parents may manipulate the actual birth dates around the reform cut-off through planned cesarean sections and labour inductions. Indeed, Neugart and Ohlsson (2013) and Tamm (2013) find that about $8 \%$ of births were shifted from the last week of December to the first week of January in a manner consistent with the economic incentives of the reform. Such strategic birth shifting introduces an endogenous sample selection bias around the reform cut-off. We address this concern by excluding children who are born in December and January from our main samples. ${ }^{22}$

Another concern regarding the sample composition would be reform affects on fertility patterns. If so, then children born in the year after the treatment cohort may show different child and family background characteristics. In Section 6.3, we show that our conclusions are the same if we exclude children born in the year after the treatment cohort from the sample. Still, we include the preceding and the subsequent cohorts in our control group to increase the sample size for more precise estimates. ${ }^{23}$

The third concern is that children may select into (or out of) the sample because of the parental leave reform, e.g. by not attending the examination. However, participation in the school entrance examination is mandatory in the year of school entry. We explicitly test for the balance of observable characteristics of the children and their family background in our samples, i.e. one sample covering all children, and two subsamples stratifying the first sample by mothers' level of education (see Table 5). As we would expect, the covariates

\footnotetext{
${ }^{22}$ Ideally, we would only drop individuals within a two-week window around January 1, but for data protection reasons the data set lacks information on the exact date of birth. Our main conclusions are robust to including children born in December and January. For details, see Section 6.3.

${ }^{23}$ The availability of publicly funded day care in Schleswig-Holstein for children aged below the age of three experienced a continuous expansion from $7.5 \%$ in 2006 to $21.6 \%$ in 2011 (German Federal Statistical Office, 2012). Our identification strategy is not affected by this expansion as it relies on the birthday eligibility cut-off of the reform. The day care expansion affects children in treatment and control cohorts born before and after the cut-off similarly.
} 
are balanced across all samples. ${ }^{24}$

The choice concerning the width of the comparison windows around the reform cut-off generates a trade-off between the precision of estimates and potential biases through differences in observable and unobservable characteristics. To maximise precision, we compare children born up to six months before and after the reform in treatment and control cohorts in our main specification. ${ }^{25}$ Empirically, we estimate the following difference-in-differences regression model:

$$
\begin{aligned}
& Y_{i}=\beta_{1} \text { treat }_{i}+\beta_{2} \text { after }_{i}+\beta_{P P L}\left(\text { treat }_{i} \cdot \text { after }_{i}\right)
\end{aligned}
$$

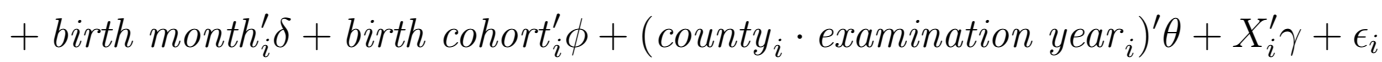

where $Y_{i}$ describes the developmental outcome for child $i$. The variable after $r_{i}$ is an indicator variable taking the value of 1 if child $i$ is born between January and June, and

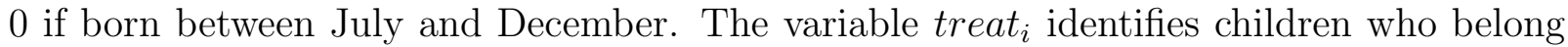
to the treatment cohort that was affected by the 2007 paid parental leave reform. It takes the value of 1 if child $i$ is born between July 2006 and June 2007, and 0 if born between July 2005 and June 2006, and July 2007 and June 2008 (i.e. one year before and after the cohort affected by the reform). The coefficient $\beta_{P P L}$ on the interaction term treat $_{i} \cdot$ after $_{i}$ identifies the intention-to-treat effect of the 2007 parental leave reform. Eligibility and take-up of paid parental leave under the new legislation was $96.3 \%$ in Germany, 96.5\% in Schleswig-Holstein (German Federal Statistical Office, 2008). In this case, the intentionto-treat effect almost corresponds to the average treatment effect on the treated (Angrist

\footnotetext{
${ }^{24}$ Delayed school entry is typically not possible in Schleswig-Holstein for cohorts in our sample. We tested whether the probability of entering school one year earlier was affected by the reform and cannot find any evidence of it. Furthermore, the reform effect on the age of children at examination, another indicator for early or delayed school entry, is very small (0.012 months with a sample mean of 72.6 months) and statistically insignificant (see Table 5).

${ }^{25}$ In Appendix Table A.3, we show that the predetermined covariates remain balanced as we increase the size of the comparison window around the cut-off.
} 
et al., 1996).

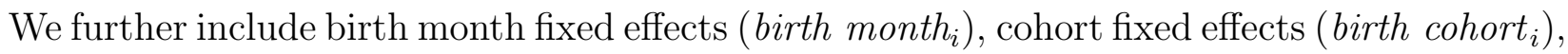
and county-year-of-examination fixed effects $\left(\right.$ county $_{i} \cdot$ examination $\left._{\text {year }}\right)$. To increase the precision of the estimates, we sequentially include additional control variables for child and family characteristics in our regressions $\left(X_{i}\right.$, containing a quartic in child's age, gender, birth weight, indicators for father's and mother's education, and indicators for whether one or both parents have a migration background).

\section{Results}

\subsection{Treatment effects on child development and SES development gaps}

We now document how the 2007 German parental leave reform affected children's development and first illustrate our results with a series of graphs. Figure 2 plots the average child outcomes by month of birth separately for children of the treatment and control cohorts. We focus on language skills, socio-emotional stability, motor skills, and school readiness. We fit linear trends separately for children born on either side of the reform cut-off on January 1 and for children of the treatment and control cohorts. We also plot average outcomes for children born in December and January, which we drop from our main estimations (see Section 5). Figure 2 shows that the trends in outcomes are fairly smooth around the cut-off for both the treated and control cohorts. Furthermore, we do not observe level shifts in child outcomes after the cut-off compared to the control group. This provides some first visual evidence that the paid parental leave reform did not have substantial effects on child outcomes. The graph also supports the common trend assumption as the trends over birth months are almost parallel between the treated and control cohorts.

To corroborate the visual evidence, Table 6 reports difference-in-differences estimates based 
on equation 1. The rows in Table 6 denote the four different dependent variables. In column 1, we only include fixed effects for birth months, birth cohorts, and county-year-ofexamination. Across the four different dimensions of child development, the point-estimates of the intention-to-treat effects are very small and statistically insignificant. In columns 2 and 3, we gradually add control variables for child and family characteristics. While the explanatory power of the model almost doubles with the inclusion of further control variables, the reform estimates remain very similar across the different specifications. The estimation results from column 3 show that the reform affected the probability of being diagnosed with a sufficient level of language skills by -0.0074 (sample mean of 0.715 ), of socio-emotional stability by -0.0035 (sample mean of 0.810 ), of motor skills by -0.0067 (sample mean of 0.825), and of being ready for school by 0.0048 (sample mean of 0.840 ). The stability of coefficients across specifications, which gradually control for relevant determinants of child development, implies that the treatment indicator is unrelated to other determinants of children's development. As these additional controls increase the precision of our estimates, we proceed with our preferred specification from column 3 in subsequent estimations.

In columns 4 and 5, we estimate the model separately by maternal education. Again, we find that the effects of the paid parental leave reform are very small across the four domains of child development, independent of maternal education. In column 6 , we statistically test whether the parental leave reform consequently affects the socio-economic gap in child development at age six. To easily assess the relative reform effects, we provide estimates of the SES gap in the absence of the reform (column 7) and with the reform (column 8). ${ }^{26}$ The effect estimates on the SES gaps in language skills (0.0089), in motor skills (-0.0076),

\footnotetext{
${ }^{26}$ The SES gap with reform in column (8) is the mean difference in the child outcome between children with high and low-/medium-educated mothers born between January and June 2007, i.e. $E\left(y_{i} \mid\right.$ mother's education $=$ high, after $=1$, treat $\left.=1\right)-E\left(y_{i} \mid\right.$ mother's education $=$ low $/$ medium, after $=$ 1 , treat $=1$ ). The SES gap w/o reform in column 7 is the SES gap with reform from column 8 less the estimated change in the SES gap reported in column 6.
} 
and in school readiness $(0.0047)$ are all very small and not statistically significant. Only the point estimate on socio-emotional stability of children suggests an increase of the gap (0.0238), but it is not statistically different from zero.

Figure 3 summarises our main findings graphically. It relates the estimated reform effects to the estimated coefficients on the child development gap in terms of mothers' education, the gender and the child's age (based on Table 4). Across all four outcomes, Figure 3 shows that our estimates are small in magnitude compared to the development gaps by mothers' education, gender, and children's age, and they are precisely estimated.

\subsection{Further treatment effect heterogeneities}

We now split the sample by children's gender to consider further heterogeneities in treatment effects of the parental leave reform (see Table 7). Ample evidence suggests that boys typically react more sensitively to changes in early childhood conditions (see, e.g. Waldfogel, 2006), so we estimate the treatment effects on child development separately by gender. The results in column 1 show that the treatment effects are qualitatively very small and not statistically different from zero for both boys and girls. In addition, no statistically significant differences of the treatment effects exist between the groups.

We also utilise different definitions of the socio-economic status. In columns 2 and 3 , we stratify the samples of boys and girls further by mothers' education. Unlike Danzer and Lavy (2016), we cannot detect significant treatment effects at this subgroup level. The main picture remains the same. ${ }^{27}$ Treatment effects are neither statistically different from zero, nor are there statistically significant differences of the treatment effects between

\footnotetext{
${ }^{27}$ Danzer and Lavy (2016) find that the 1990 paid parental leave expansions in Austria had positive (negative) effects on sons of highly (low-) educated mothers. The differences in findings are likely due to differences in the child development phases, as well as the usage and quality of alternative care arrangements. In our setting, the availability of publicly funded day care is very low, and the common alternative child care is provided by grandparents and relatives. The quality differences to maternal care are presumably small.
} 
girls and boys. In columns 4 and 5, we stratify the sample by paternal education. The same picture emerges, but the effects are less precisely estimated as the data lacks more information on fathers' than on mothers' education. ${ }^{28}$

In columns 6 and 7, we stratify the sample by the highest level of education of either parent. None of the estimated effects is statistically different from the corresponding estimates in columns 2 and 3. One negative coefficient estimate on the socio-emotional stability of girls from lower educated households now turns significant at the $5 \%$-level $(p=0.044)$. We are careful in interpreting the coefficient as a real treatment effect, as it is neither robust to different sample definitions and model specifications, nor can we rule out significance due to multiple hypotheses testing. ${ }^{29}$ We conclude that our results do not reveal any evidence of treatment effects of the 2007 paid leave reform on children's outcomes in any of the subgroups we consider.

Finally, we analyse whether the reform affected child development in other parts of the child development distribution that the development indicators employed in the main analysis miss. Some counties provide information on the specific test results the binary assessments are based on. In Table A.2, we repeat the analysis on the specific test results of children, and on dummies representing different positions of children in the specific test distribution. We cannot find any support for differential effects across the distribution of child development in language skills, motor skills and socio-emotional behaviour. This provides some confidence that our main child outcomes do not hide important effect heterogeneities across the distribution of outcomes.

\footnotetext{
${ }^{28}$ The information on paternal education is missing for $23.8 \%$ of children in the sample. For maternal education, we lack information from $18.3 \%$ of children in the sample. In Table 5 we show that missing information of parental education is unrelated to the parental leave reform.

${ }^{29}$ In Table 7 we test 56 hypotheses of which one rejects the null. This is fewer than what we would expect by chance.
} 


\subsection{Sensitivity checks}

Table 8 presents various robustness checks to assess the sensitivity of our results to varying sample definitions and model specifications. ${ }^{30}$ The difference-in-differences model rests on the assumption that age-at-examination effects and seasonal birth effects are the same for the treated and the control cohorts. While a larger comparison window increases the sample size and statistical power, the potential impact of such age and seasonal effects may increase as one moves away from the reform cut-off. To check this potential issue, we gradually narrow the window of comparison from six to two months on both sides of the cut-off across columns 2 to 5 . As before, we remove children born in December and January from our sample. ${ }^{31}$ Our results show that the estimated coefficients are still small, and not statistically different from our main specification. As we would expect, the standard errors of the estimated treatment effects increase as we narrow the window of comparison. We conclude that our main results are not biased by using a 6-month window.

Alternatively, we could include further control cohorts from earlier years. While additional control cohorts may increase the precision of the estimates, these cohorts may also confound the estimated reform effects, for example, because of different unobserved treatments to the control cohorts. Column 6 shows that including children born between July 2004 and June 2005 in the control group increases the sample size by about one third, but the coefficients do not change much. As the gain in the precision of our estimates is small, it is not our preferred specification. ${ }^{32}$

Given the evidence of birth shifting that is related to potential reform benefits, we dropped

\footnotetext{
${ }^{30}$ We also run all robustness checks separately by maternal education. Table A.4 shows that our conclusions are robust for the subsamples.

${ }^{31}$ Predetermined variables are balanced across all window sizes, see Appendix Table A.3.

${ }^{32}$ To further increase precision, we pool all outcomes and estimate the treatment effect with our main specification further allowing for level differences in the outcome variables. While this assumes that the reform had the same impact on all outcomes, it increases the sample size and leads to even more precise estimates. Table A.5 shows that we reach the same conclusions.
} 
children born in December or January from our main specifications. In column 7, we assess the sensitivity of results by including children born in December and January in our main sample. Our conclusions are the same.

Next, we assess whether any endogenous fertility effects may bias our estimates. Fertility responses might affect children from the control group born one year after the treatment cohort. Column 8 shows that excluding children born after July 2007 generates estimates that are very similar to our main specification.

Since our outcome variables are measured as dummy variables, columns 9 and 10 report the marginal effects on the interaction term of equation 1 from probit and logit models (Puhani, 2012). The estimated reform effects are very similar and again not statistically different from zero.

We assess the plausibility of the common trend assumption with a set of robustness checks reported in Table $9 .^{33}$ First, we substitute the birth months fixed effects from our main model with linear (column 2) and quadratic (column 3) cohort-specific time trends. The treatment effect is now identified by differential jumps in the trends on January 1 between treatment and control cohorts; reassuringly, we reach the same conclusions. We additionally run two placebo policy reforms at points in time in which no treatment occurred. In the first placebo test, we pretend that the reform was implemented one year earlier. The second test assumes that the parental leave reform was implemented on April 1, 2007. For the second placebo test, we restrict the sample to children born three months before and after the placebo cut-off to avoid overlaps with the real cut-off, and specify the differencein-differences model analogously to equation 1. The difference-in-differences estimates of both placebo tests are reported in columns 4 and 5 of Table 9 . The estimates of both placebo tests are close to zero and statistically insignificant, supporting the common trend

\footnotetext{
${ }^{33}$ The same set of robustness checks is performed on the stratified samples by maternal education. The results are reported in Appendix Table A.6.
} 
assumption between treatment and control cohorts.

Finally, we alternatively use a regression discontinuity design to identify the treatment effects. Given only five birth months on each side of the cut-off, we assume a linear trend in the outcome variables across birth months for children born between July 2006 and June 2007 and identify the treatment effect with an indicator for children born on or after January 1, 2007. The results are reported in column 6 of Table 9. ${ }^{34}$ Across the four dimensions of child development, the treatment effect is not statistically different from zero.

\section{Discussion}

Despite the substantial changes resulting from the 2007 paid parental leave reform in Germany, we find no evidence that the reform impacted any of the four important dimensions of child development and SES development gaps. One explanation could be that we miss out heterogeneous treatment effects. The reform affected families differently depending on their household income and mothers' pre-birth earnings. Although we lack this information in our data, we have information on parental education, which is positively correlated with earnings and household income. Table 1 demonstrates that the distinction by mothers' education separates the sample in two distinct groups that benefited very differently from the reform. This distinction is commonly used when SES gaps in opportunitities or in child development are discussed (see, e.g. Bradbury et al., 2015). Although the stratification by maternal education does not perfectly mimic families' pre-reform eligibility for paid parental leave, it reflects groups of families with very different shares of previous eligibility. As we additionally benefit from a large sample size and professional medical screenings, we should be able to detect even small effects (or tendencies, if any). Moreover,

\footnotetext{
${ }^{34} \mathrm{As}$ in the main specification, the underlying sample excludes children born in December and January. The results are similar if we include them in the sample.
} 
we run our analyses in subsamples stratified by paternal and by highest household level of education, and cannot detect such effects. We further stratify the subsamples by gender, as boys typically react more sensitively to changes in early childhood conditions. Still, we cannot detect effects of the reform on child development. Therefore, we would expect that a further refinement of groups would also not lead to large treatment effects.

More likely explanations for the zero-reform effects are provided by the recent economic literature on determinants of child development. ${ }^{35}$ We discuss the potential channels for the two groups experiencing the most extreme reform changes: previously ineligible mothers who gain first-time eligibility for up to one year and previously eligibile mothers who lost entitlement for the second year. Within these groups, we discuss the impact of changes along three different phases of child development: 0 to 6 months, 7 to 12 months, and 12 to 24 months after childbirth. For mothers in between both groups, the main arguments apply similarly.

Mothers who gained new eligibility for paid parental leave stayed at home during the first eight weeks after childbirth because of the unchanged universal mother protection period with fully compensated pre-birth earnings (see Section 3). After these eight weeks, a substantial share of newly eligible mothers took unpaid parental leave within the first six months after childbirth before the reform (Bergemann and Riphahn, 2015; Welteke and Wrohlich, 2016). During this early phase following childbirth, the reform has largely substituted unpaid leave with paid leave. Effectively, newly eligible families receive unrestricted income transfers which Heckman and Mosso (2014) and Del Boca et al. (2016) suggest to be ineffective at affecting child development. Moreover, the changes in benefits

\footnotetext{
${ }^{35}$ Given that the production of children's skills is a very complex process in which the timing of investments, dynamic complementarities in inputs, self-productivity of skills, and endogenous reactions of parental investments to children's development are important interrelated determinants (see, e.g. Todd and Wolpin, 2007; Cunha and Heckman, 2007; Fiorini and Keane, 2014), it is particularly hard to identify single channels through which changes in early conditions affect later child outcomes. While our data has a unique advantage in the measurements for child development, it lacks information on parental investments into children.
} 
can be interpreted as an exogenous transitory household income shock. In line with a large body of the previous consumption literature, Carneiro and Ginja (2016) demonstrate that parents do not adjust their child investments in terms of time and goods to transitory income shocks. Therefore, investments in the first six months likely remained constant. ${ }^{36}$

Between 7 to 12 months after childbirth, newly eligible mothers responded to the reform with a reduction in their employment, which was mostly part-time (Bergemann and Riphahn, 2015). Reviewing the findings on the effects of maternal employment in the first year after childbirth on child development, Brooks-Gunn et al. (2010) and Bernal and Keane (2010) conclude that the effects are rather small, especially for part-time employment beyond the initial six months following childbirth. Therefore, reform-related changes in mothers' employment behaviour are also unlikely to have a considerable impact on child development. This is also consistent with Dahl et al. (2016), who analyse an expansion of paid parental leave in Norway within the first year after childbirth. While the reform induced women to almost completely substitute work with the new paid parental leave, they find no impact on children's long-term outcomes.

After the first 12 months following childbirth, some evidence suggests that newly eligible mothers were now also more likely to work (Bergemann and Riphahn, 2015). The effects of maternal employment beyond the first year after childbirth on children critically depend on the quality of alternative care arrangements. As the availability of publicly funded day care for children below the age of three was very low, informal child care by grandparents or other relatives was the main alternative mode of care when mothers were working (Hank and Buber, 2009). However, the decision to work is endogenous, and mothers may only be willing to return to work if they can ensure alternative care arrangements of comparable

\footnotetext{
${ }^{36}$ Dahl and Lochner (2012) and Løken et al. (2012) provide evidence for effects of family income on child outcomes, but they do not decompose family inome in its permanent and transitory components. Carneiro and Ginja (2016) find effects on parental child investments only for changes in permanent income. Further evidence that permanent income rather than transitory income fluctuations matter for child development is provided by Cameron and Heckman (1998) and Bernal and Keane (2010).
} 
quality to their own care. With little quality differences between maternal and alternative child care, increases in maternal employment are also unlikely to have a large impact on children.

We now turn to children of mothers who where previously eligible, but lost eligibility for paid parental leave in the second year after childbirth (about $40 \%$ of mothers). In the period 0 to 12 month after childbirth, these mothers still receive at least the same amount of benefits, such that parents could direct the same investments (time and goods) toward their children.

In the second year after childbirth, these families experience a negative transitory income shock that they partly compensate for with increased maternal employment (Kluve and Schmitz, 2014; Bergemann and Riphahn, 2015) allowing them to maintain their material investments in children. The additional time spent working reduces the time mothers can spend with their children. Whether this affects child development depends on the activities both the mother and the alternative caregiver perform with the children: First, Del Bono et al. (2016) note that the educational activities mothers perform with their children correlate only weakly with maternal employment. Second, Hsin and Felfe (2014) suggest that maternal employment has no impact on maternal activities that positively affect children, while it reduces the time they spend on activities that are unproductive or even detrimental for child development. Third, the quality of alternative care is unlikely to differ much from maternal care as it is mostly provided by informal caregivers. ${ }^{37}$ Taken together, reforminduced transitory income shocks are unlikely to change parents' productive investments (material and time) in their children, as suggested by Carneiro and Ginja (2016).

Overall, recent studies examining determinants of early child development provide plausible arguments for zero-effects of the paid parental leave reform on child development at age 6 .

\footnotetext{
${ }^{37}$ Alternative care provided by the universal day care system in Germany is of relatively high quality (e.g. Spiess and Wrohlich, 2008) and thus unlikely to differ much from maternal care.
} 


\section{Conclusion}

In this paper, we examine the effects of a recent and substantial German paid parental leave reform on child development. The 2007 reform replaced a means-tested system with an earnings-dependent benefit system, such that (substantial) gains in parental leave benefits increased with mothers' pre-birth earnings and household income. We examine the effects on the development of children at age six from low- and high-SES families to investigate whether the reform impacted pre-existing, substantial, SES gaps in child development.

To estimate the causal reform effect, we use a difference-in-differences identification strategy that makes use of the sharp eligibility criterion for the new benefit system based on children's birth date. We employ an exceptionally rich data source of child development: Administrative, mandatory, and full population child development assessments from school entrance examinations from one German federal state. Our results provide new evidence that the drastic change in the parental leave benefit system had no impact on various measures for children's development at age six. Most point estimates are very close to zero and precisely estimated. We do not find effects on children from high-SES families, on children from low-SES families, or on SES gaps in child development. Our results are robust to numerous sensitivity checks accounting for endogenous sample selection, variations to the estimation window and control cohorts, different sets of control variables, redefinitions of outcome measures, and alternative estimation methods and assumptions on time trends.

Our zero-reform effects are consistent with recent economic studies on the determinants of child development. In particular, Carneiro and Ginja (2016) show that temporary household income shocks do not change parents' productive investments and Heckman and Mosso (2014, p. 3) conclude that unrestricted income transfers "are a weak reed" to affect child outcomes. Moreover, the reform largely affected maternal labour supply at

margins that have, at most, a small impact on child development (Bernal and Keane, 2010; Brooks-Gunn et al., 2010). 
As with any other study, our analysis also has some limitations. While we are able to reliably estimate the reform effects for parents immediately affected by the reform, our empirical strategy cannot capture reform effects that unfold gradually over time, such as changes in social norms related to maternal labour supply and paternal leave taking (Kluve and Schmitz, 2014; Bergemann and Riphahn, 2015; Welteke and Wrohlich, 2016). For example, mothers may decide to give birth at a higher age when they are more strongly attached to the labour market, which may itself have consequences for children's development. Furthermore, the reform may have impacted other dimensions of child outcomes that are not reflected in the rich set of child development measures that we examine.

What do our results mean for public policy? Since most OECD countries now have paid parental leave policies in place, governments are mainly interested in re-designing these regulations to better incentivise female labour supply, fertility, or paternal involvement in the child rearing process. The German reform effectively changed maternal labour supply, family income, and paternal leave-taking. In light of these findings, our study suggests that such policy objectives can be achieved without adverse effects on children's development or the SES development gap.

Acknowledgements We are grateful for comments and suggestions by Wiji Arulampalam, Stefan Bauernschuster, Pedro Carneiro, Claire Crawford, Kamila Cygan-Rehm, Victor Lavy, Michael Oberfichtner, Regina T. Riphahn, Pia Schober, Felix Weinhardt, Vaishali Zambre, participants of the "Early Childhood Inequality Workshop" in Nuremberg and the 2016 meeting of the "Ausschuss für Sozialpolitik" in Mannheim. Special thanks go to the Ministry of Social Affairs, Health, Family and Equal Opportunities in Schleswig-Holstein, in particular to Sabine Brehm and Prof. Dr. Ute Thyen for providing data access and significant support. Mathias Huebener acknowledges financial support by the German National Academic Foundation. Daniel Kuehnle acknowledges financial support by the German Science Foundation (DFG SPP 1764). 


\section{References}

Almond, D. and J. Currie (2011). Human capital development before age five. In O. Ashenfelter and D. Card (Eds.), Handbook of Labor Economics, Volume 4b, Chapter 15, pp. 1315-1486. North Holland.

Angrist, J. D., G. W. Imbens, and D. B. Rubin (1996). Identification of causal effects using instrumental variables. Journal of the American Statistical Association 91(434), $444-455$.

Angrist, J. D., V. Lavy, and A. Schlosser (2010). Multiple experiments for the causal link between the quantity and quality of children. Journal of Labor Economics 28(4), 773-824.

Autorengruppe Bildungsberichterstattung (2016). Bildung in Deutschland 2016. Ein indikatorengestützter Bericht mit einer Analyse zu Bildung und Migration. Bielefeld: W. Bertelsmann Verlag.

Baker, M. and K. Milligan (2010). Evidence from maternity leave expansions of the impact of maternal care on early child development. Journal of Human Resources 45(1), 1-32.

Baker, M. and K. S. Milligan (2008). Maternal employment, breastfeeding, and health: Evidence from maternity leave mandates. Journal of Health Economics 27(4), 871-887.

Baker, M. and K. S. Milligan (2015). Maternity leave and childrens cognitive and behavioural development. Journal of Population Economics 28(2), 373-391.

Becker, G. S. and H. G. Lewis (1974). Interaction between quantity and quality of children. In Economics of the family: Marriage, children, and human capital, pp. 81-90. University of Chicago Press.

Bergemann, A. and R. T. Riphahn (2015). Maternal employment effects of paid parental leave. IZA Discussion Paper Series 9073.

Berger, L. M., J. L. Hill, and J. Waldfogel (2005). Maternity leave, early maternal employment and child health and development in the US. The Economic Journal 115(501), F29-F47.

Bernal, R. and M. P. Keane (2010). Quasi-structural estimation of a model of childcare choices and child cognitive ability production. Journal of Econometrics 156(1), 164-189.

Beuchert, L. V., M. K. Humlum, and R. Vejlin (2016). The length of maternity leave and family health. Labour Economics 43, 55-71.

Björklund, A. and K. G. Salvanes (2011). Education and family background: Mechanisms and policies. In E. Hanushek, S. Machin, and L. Woessmann (Eds.), Handbook of Economics of Education, Volume 3, Chapter 3, pp. 201-247. Amsterdam, London, North Holland: Elsevier. 
Blanden, J., P. Gregg, and L. Macmillan (2007). Accounting for intergenerational income persistence: Noncognitive skills, ability and education. The Economic Journal 117(519), C43-C60.

Borra, C., M. Iacovou, and A. Sevilla (2012). The effect of breastfeeding on children's cognitive and noncognitive development. IZA Discussion Paper Series $669 \%$.

Bradbury, B., M. Corak, J. Waldfogel, and E. Washbrook (2015). Too many children left behind: The US achievement gap in comparative perspective. Russell Sage Foundation.

Bradley, R. H. and R. F. Corwyn (2002). Socioeconomic Status and Child Development. Annual Review of Psychology 53(1), 371-399.

Brooks-Gunn, J., W.-J. Han, and J. Waldfogel (2010). First-year maternal employment and child development in the first seven years. Monographs of the Society for Research in Child Development 75, 1-147.

Bujard, M. (2013). Die fünf Ziele des Elterngelds im Spannungsfeld von Politik, Medien und Wissenschaft. Zeitschrift für Familienforschung 25(2), 132-153.

Cameron, S. and J. J. Heckman (1998). Life cycle schooling and dynamic selection bias: Models and evidence for five cohorts of American males. Journal of Political Economy 106 (2), 262-333.

Carneiro, P., C. Crawford, and A. Goodman (2007). The impact of early cognitive and noncognitive skills on later outcomes. Centre for the Economics of Education Discussion Paper 92.

Carneiro, P. and R. Ginja (2016). Partial insurance and investments in children. The Economic Journal 126(596), F66-F95.

Carneiro, P., K. V. Løken, and K. G. Salvanes (2015). A flying start? Maternity leave benefits and long-run outcomes of children. Journal of Political Economy 123(2), 365412.

Cunha, F. and J. Heckman (2007). The technology of skill formation. American Economic Review 97(2), 31-47.

Cunha, F., J. J. Heckman, L. Lochner, and D. V. Masterov (2006). Interpreting the evidence on life cycle skill formation. In E. Hanushek and F. Welch (Eds.), Handbook of Economics of Education, Volume 1 of Handbook of the Economics of Education, Chapter 12, pp. 697-812. Amsterdam: North Holland.

Cygan-Rehm, K. (2016). Parental leave benefit and differential fertility responses: evidence from a German reform. Journal of Population Economics 29(1), 73-103.

Dahl, G. B. and L. J. Lochner (2012). The impact of family income on child achievement: Evidence from the earned income tax credit. American Economic Review 102(5), 19271956. 
Dahl, G. B., K. V. Løken, M. Mogstad, and K. V. Salvanes (2016). What is the case for paid maternity leave? The Review of Economics and Statistics 98(4), 655-670.

Danzer, N. and V. Lavy (2016). Paid parental leave and children's schooling outcomes. The Economic Journal, forthcoming.

Del Boca, D., C. Flinn, and M. Wiswall (2016). Transfers to households with children and child development. The Economic Journal 126(596), F136-F183.

Del Bono, E., M. Francesconi, Y. Kelly, and A. Sacker (2016). Early maternal time investment and early child outcomes. The Economic Journal 126(596), F96-F135.

Duncan, G. J., C. J. Dowsett, A. Claessens, K. Magnuson, A. C. Huston, P. Klebanov, L. S. Pagani, L. Feinstein, M. Engel, J. Brooks-Gunn, H. Sexton, K. Duckworth, and C. Japel (2007). School readiness and later achievement. Developmental Psychology 43(6), 14281446.

Dustmann, C. and U. Schönberg (2011). Expansions in maternity leave coverage and children's long-term outcomes. American Economic Journal: Applied Economics 4(3), 190-224.

Federal Ministry of Finance (2007). Haushaltsrechnung und Vermögensrechnung des Bundes für das Haushaltsjahr 2006 (Jahresrechnung 2006). Bundesministerium der Finanzen.

Feinstein, L. (2003). Inequality in the early cognitive development of British children in the 1970 cohort. Economica $70(277), 73-97$.

Fiorini, M. and M. P. Keane (2014). How the allocation of children's time affects cognitive and non-cognitive development. Journal of Labor Economics 4(32), 787-836.

German Federal Statistical Office (2008). Öffentliche Sozialleistungen. Statistik zum Elterngeld. Elterngeld für Geburten 2007 Anträge von Januar 2007 bis Juni 2008. Statistisches Bundesamt, Wiesbaden.

German Federal Statistical Office (2012). Kindertagesbetreuung in Deutschland 2012. Statistisches Bundesamt, Wiesbaden.

German Federal Statistical Office (2016). Volkswirtschaftliche Gesamtrechnung der Länder: Bruttoinlandsprodukt - in jeweiligen Preisen - 1991 bis 2015. Statistische Ämter des Bundes und der Länder, Wiesbaden.

Geyer, J., P. Haan, and K. Wrohlich (2015). The effects of family policy on maternal labor supply: Combining evidence from a structural model and a quasi-experimental approach. Labour Economics 36, 84-98.

Gimenez-Nadal, J. I. and J. A. Molina (2013). Parents' education as a determinant of educational childcare time. Journal of Population Economics 26(2), 719-749. 
Goodman, R., H. Meltzer, and V. Bailey (1998). The strengths and difficulties questionnaire: A pilot study on the validity of the self-report version. European child \& adolescent psychiatry 7(3), 125-130.

Grissmer, D., K. J. Grimm, S. M. Aiyer, W. M. Murrah, and J. S. Steele (2010). Fine motor skills and early comprehension of the world: Two new school readiness indicators. Developmental Psychology 46(5), 1008-1017.

Haan, P. and K. Wrohlich (2011). Can child care policy encourage employment and fertility? Evidence from a structural model. Labour Economics 18(4), 498-512.

Hank, K. and I. Buber (2009). Grandparents caring for their grandchildren: Findings from the 2004 Survey of Health, Ageing, and Retirement in Europe. Journal of Family Issues $30(1), 53-73$.

Heckman, J. J. and S. Mosso (2014). The economics of human development and social mobility. Annual Review of Economics 6(1), 689-733.

Hsin, A. and C. Felfe (2014). When does time matter? Maternal employment, children's time with parents, and child development. Demography 51(5), 1867-1894.

Huber, K. (2015). Moving to an earnings-related parental leave system - do heterogeneous effects on parents make some children worse off? SOEPpapers on Multidisciplinary Panel Data Research 791.

Huebener, M. (2016). Parental leave policies and child development: A review of empirical findings. DIW Roundup Politik im Fokus No. 102.

Huebener, M., K.-U. Müller, C. K. Spieß, and K. Wrohlich (2016). The parental leave benefit: A key family policy measure, one decade later. DIW Economic Bulletin 6(49), $571-578$.

Kalil, A., R. Ryan, and M. Corey (2012). Diverging destinies: Maternal education and the developmental gradient in time with children. Demography 49(4), 1361-1383.

Kluve, J. and S. Schmitz (2014). Social norms and mothers' labor market attachment. The medium-run effects of parental benefits. IZA Discussion Paper Series 8115.

Kluve, J. and M. Tamm (2013). Parental leave regulations, mothers' labor force attachment and fathers' childcare involvement: Evidence from a natural experiment. Journal of Population Economics 26(3), 983-1005.

Kottwitz, A., A. Oppermann, and C. K. Spiess (2016). Parental leave benefits and breastfeeding in Germany: Effects of the 2007 reform. Review of Economics of the Household 14(4), 859-890.

Lalive, R. and J. Zweimüller (2009). How does parental leave affect fertility and return to work? Evidence from two natural experiments. Quarterly Journal of Economics 124(3), 1363-1402. 
Leibowitz, A. (1977). Parental inputs and children's achievement. Journal of Human Resources 12(2), 242-251.

Liu, Q. and O. N. Skans (2010). The duration of paid parental leave and children's scholastic performance. B.E. Journal of Economic Analysis 65 Policy Contributions 10(1), 1-33.

Løken, K. V., M. Mogstad, and M. Wiswall (2012). What linear estimators miss: The effects of family income on child outcomes. American Economic Journal: Applied Economics 4(2), 1-35.

Maggi, S., L. J. Irwin, A. Siddiqi, and C. Hertzman (2010). The social determinants of early child development: An overview. Journal of Paediatrics and Child Health 46(11), $627-635$.

Neugart, M. and H. Ohlsson (2013). Economic incentives and the timing of births: Evidence from the German parental benefit reform 2007. Journal of Population Economics 26(1), $87-108$.

OECD (2016a). OECD data fertility rates (indicator). Retrieved from https://data.oecd.org/pop/fertility-rates.htm, downloaded in December, 2016.

OECD (2016b). OECD Family Database: Enrolment in childcare and pre-school. OECD - Social Policy Division - Directorate of Employment, Labour and Social Affairs.

OECD (2016c). OECD Family database: Maternal employment. OECD - Social Policy Division - Directorate of Employment, Labour and Social Affairs.

OECD (2016d). OECD Family Database: Trends in parental leave policies since 1970. OECD - Social Policy Division - Directorate of Employment, Labour and Social Affairs.

Ondrich, J., C. K. Spiess, and Q. Yang (1996). Barefoot and in a German kitchen: Federal parental leave and benefit policy and the return to work after childbirth in Germany. Journal of Population Economics 9, 247-266.

Puhani, P. A. (2012). The treatment effect, the cross difference, and the interaction term in nonlinear "difference-in-differences" models. Economics Letters 115(1), 85-87.

Rossin, M. (2011). The effects of maternity leave on children's birth and infant health outcomes in the united states. Journal of Health Economics 30(2), 221-239.

Ruhm, C. J. (2000). Parental leave and child health. Journal of Health Economics 19(6), 931-960.

Schnabel, C. (2016). United, yet apart? A note on persistent labour market differences between Western and Eastern Germany. Jahrbücher fur Nationalökonomie und Statistik 236(2), 157-179. 
Schober, P. S. and C. K. Spiess (2013). Early childhood education activities and care arrangements of disadvantaged children in Germany. Child Indicators Research 6(4), 709-735.

Schönberg, U. and J. Ludsteck (2014). Expansions in maternity leave coverage and mothers' labor market outcomes after childbirth. Journal of Labor Economics 32(3), 469-505.

Spiess, C. K. and K. Wrohlich (2008). The parental leave benefit reform in Germany: Costs and labour market outcomes of moving towards the nordic model. Population Research and Policy Review 27(5), 575-591.

Tamm, M. (2013). The impact of a large parental leave benefit reform on the timing of birth around the day of implementation. Oxford Bulletin of Economics and Statistics 75(4), $585-601$.

Tanaka, S. (2005). Parental leave and child health across OECD countries. The Economic Journal 115(501), F7-F28.

Todd, P. and K. Wolpin (2007). The production of cognitive achievement in children: home, school, and racial test score gaps. Journal of Human Capital 1(1), 91-136.

Wagner, G. G., J. R. Frick, and J. Schupp (2007). The German Socio-Economic Panel Study (SOEP): Scope, evolution and enhancements. Schmollers Jahrbuch 127(1), 139169.

Waldfogel, J. (2006). What children need. Cambridge, MA: Havard University Press.

Welteke, C. and K. Wrohlich (2016). Peer effects in parental leave decisions. DIW Discussion Paper 1600.

Wrohlich, K., E. Berger, J. Geyer, P. Haan, D. Sengül, C. K. Spieß, and A. Thiemann (2012). Elterngeld Monitor. Deutsches Institut für Wirtschaftsforschung.

Würtz Rasmussen, A. (2010). Increasing the length of parents' birth-related leave: The effect on children's long-term educational outcomes. Labour Economics 17(1), 91-100. 


\section{Figures}

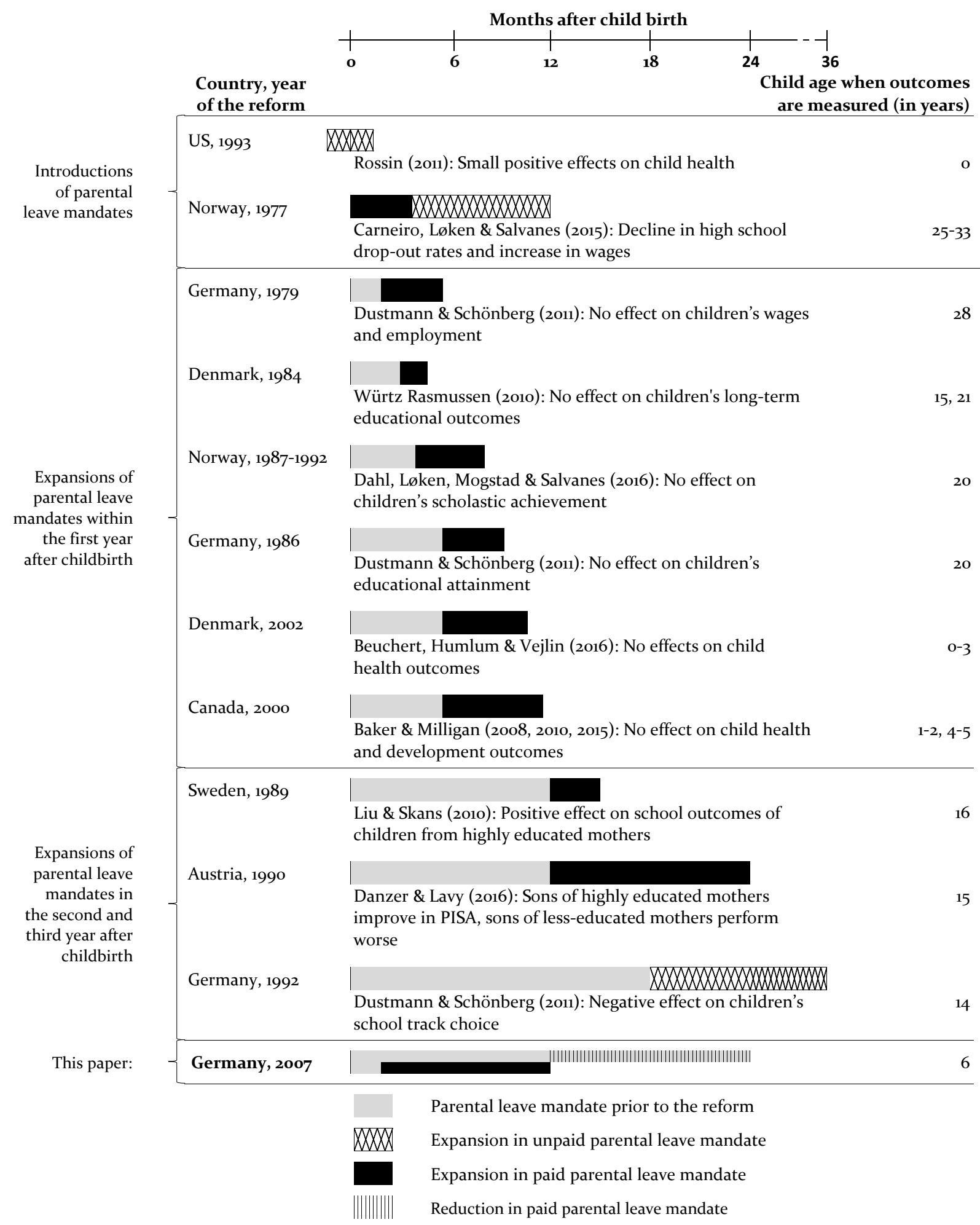

Figure 1: Evaluated parental leave reforms and their impact on child outcomes

Notes: This figure provides an overview of peer-reviewed economic studies evaluating parental leave reforms and their impact on child outcomes in individual level data. Source: Illustration based on Huebener (2016). 

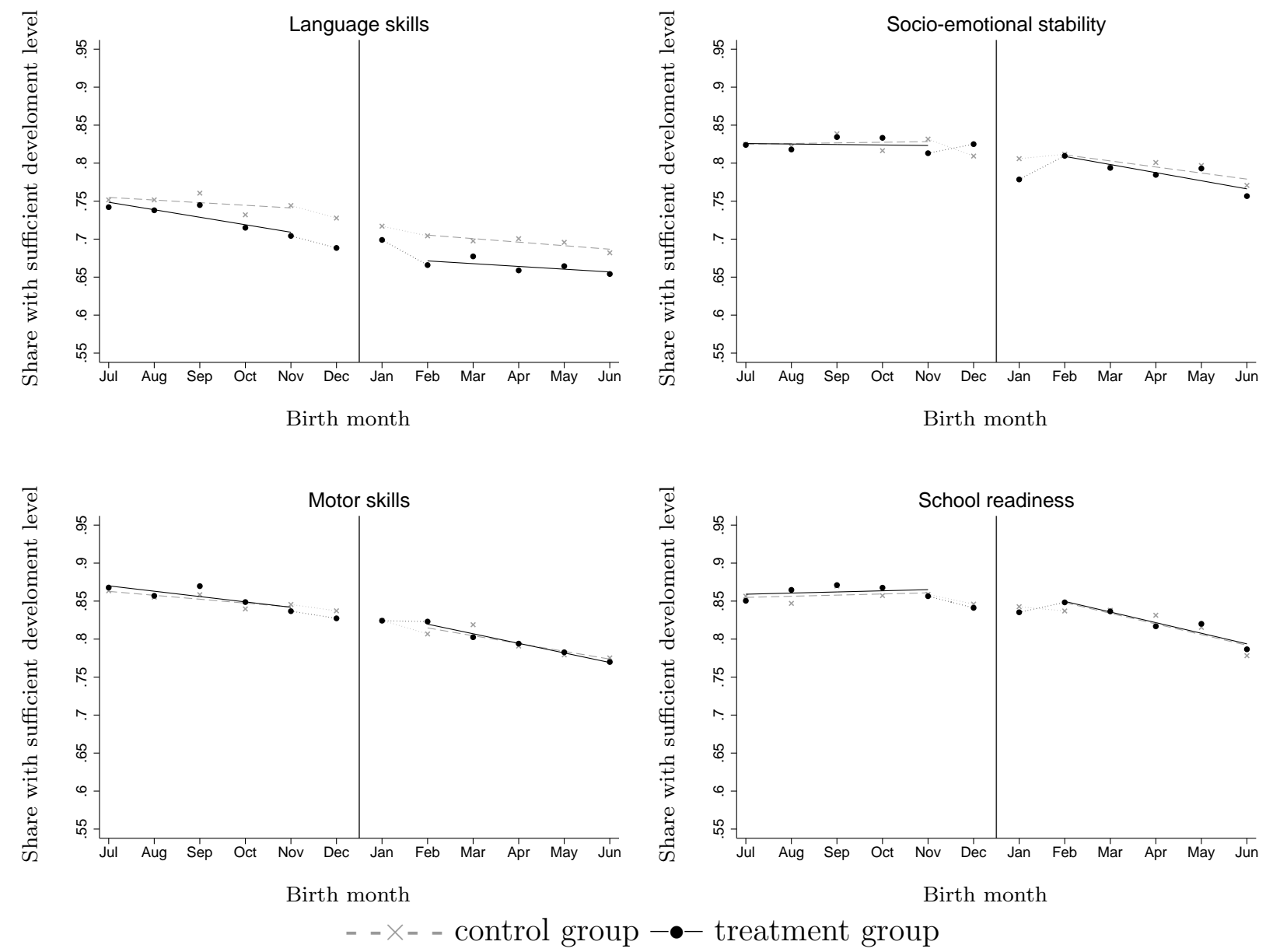

Figure 2: The impact of the 2007 German parental leave reform on child development

Notes: The figure plots the share of children diagnosed with a sufficient level of the respective skill for children born 6 months before and 6 months after the new parental leave legislation in Germany (treatment group), and for children born in the same months 6 months before and 6 months one year before and one year after (control group). The vertical bar between December and January indicates the introduction of the reform on January 1, 2007. The solid and dashed lines represents linear fits for children in our main sample. The dotted lines refer to children in months that are likely to be affected by birth date manipulations. They are exempted from our main analyses.

Source: Own calculations based on school entrance examinations for Schleswig-Holstein for children born between July 2005 and June 2008. 


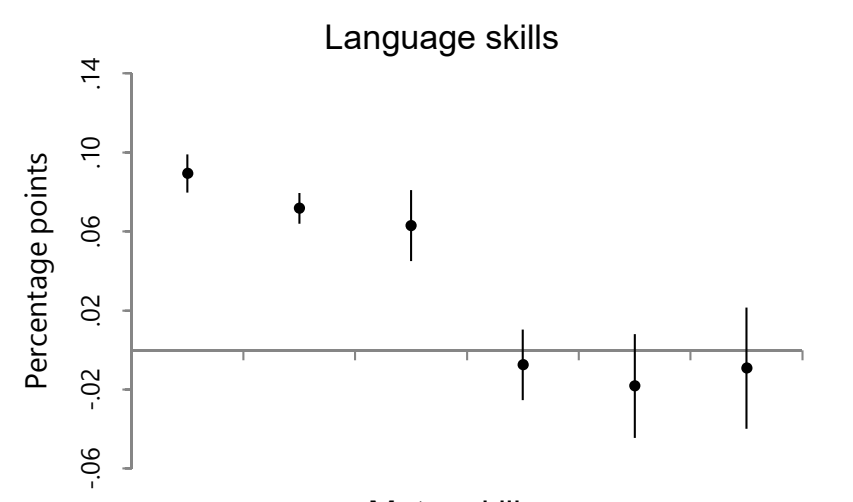

Motor skills
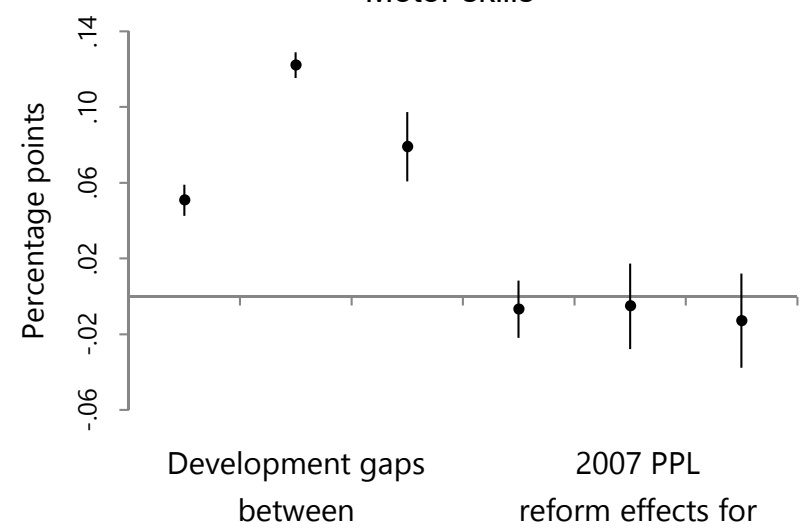



School readiness

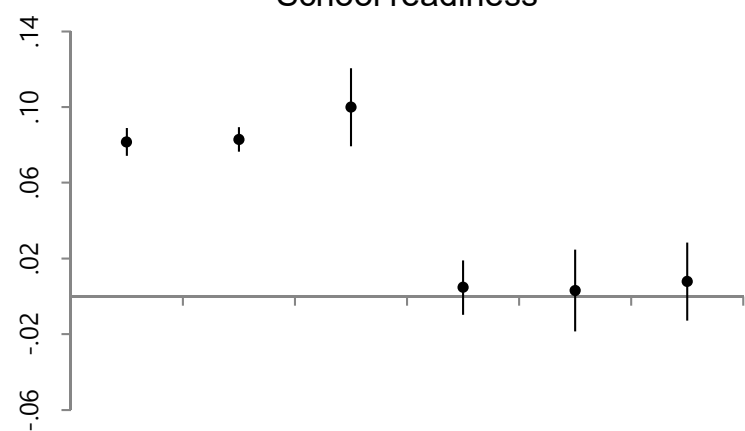



Figure 3: Comparing child development gaps by mothers' education, gender and child age to treatment effect sizes of the 2007 German parental leave reform

Notes: The figure plots child development gaps at school entrance (coefficient estimates retrieved from Table 4, coefficient on age is scaled), and estimated treatment effects of the 2007 German paid parental leave reform for all children, for children from low/medium educated mothers and from highly educated mothers. Bars indicate the $95 \%$ confidence interval of the estimated coefficients.

Source: Own calculations based on school entrance examinations for Schleswig-Holstein for children born between July 2005 and June 2008. 


\section{Tables}

Table 1: Parental benefit eligibility for parents of children born before and on or after January 1, 2007

\begin{tabular}{lccc}
\hline & & \multicolumn{2}{c}{ Mothers' education } \\
\cline { 3 - 4 } & All & Low \& medium & High \\
\hline Pre-birth household annual net income in EUR & $31,712.29$ & $27,267.56$ & $37,530.56$ \\
\hline Children born before January 1, 2007: Erziehungsgeld & & \\
\% recipients for 1-6 months & 77.25 & 84.13 & 71.07 \\
\% recipients for 6-12 months & 47.11 & 52.98 & 39.80 \\
\% recipients for > 12 months & 39.91 & 45.34 & 33.02 \\
\hline $\mathrm{N}$ & 311 & 173 & 138 \\
\hline Children born on or after January 1, 200\%: Elterngeld & & \\
\% recipients & nearly $100 \%$ & nearly $100 \%$ & nearly $100 \%$ \\
Monthly benefits of the mothers in EUR & 634.28 & 562.72 & 771.12 \\
\% fathers taking parental leave & 12.81 & 9.32 & 20.85 \\
Monthly benefits of the fathers in EUR & $1,060.52$ & 864.11 & $1,190.43$ \\
\hline $\mathrm{N}$ & 197 & 124 & 73 \\
\hline
\end{tabular}

Notes: Descriptive statistics on parental benefits for parents of children born two years before and two years after the 2007 German paid parental leave reform (2005 through 2008). Statistics exclude civil servants and self-employed mothers, and consider household weights in the year of birth of the child. Survey information is cleaned based on plausibility checks on duration, amount and eligibility criteria under consideration of the provided net household income information.

Source: Own calculations based on SOEPv30 for children born in 2005 through 2008. 
Table 2: Changes in parental benefits in the first two years after childbirth after the 2007 German paid parental leave reform

\begin{tabular}{|c|c|c|c|}
\hline & & \multicolumn{2}{|c|}{ Changes in paid parental leave } \\
\hline & & 1st year after birth & 2nd year after birth \\
\hline $\begin{array}{l}\text { Before } 2007 \text { reform: } \\
\text { After } 2007 \text { reform: }\end{array}$ & $\begin{array}{l}\text { Ineligible or eligible } \\
\text { for up to } 6 \text { months } \\
\text { Eligible }\end{array}$ & $\begin{array}{l}\text { PPL benefits } \uparrow \\
\text { PPL duration } \uparrow\end{array}$ & No change \\
\hline $\begin{array}{l}\text { Before } 2007 \text { reform: } \\
\text { After } 2007 \text { reform: }\end{array}$ & $\begin{array}{l}\text { Eligible } \\
\text { Minimum benefits }\end{array}$ & No change & $\begin{array}{l}\text { PPL benefits } \downarrow \\
\text { PPL duration } \downarrow\end{array}$ \\
\hline $\begin{array}{l}\text { Before } 2007 \text { reform: } \\
\text { After } 2007 \text { reform: }\end{array}$ & $\begin{array}{l}\text { Eligible } \\
>\text { minimum benefits }\end{array}$ & $\begin{array}{l}\text { PPL benefits } \uparrow \\
\text { PPL duration }\end{array}$ & $\begin{array}{l}\text { PPL benefits } \downarrow \\
\text { PPL duration } \downarrow\end{array}$ \\
\hline
\end{tabular}

Notes: This table describes the effects on paid parental leave (PPL) eligibility and benefit payments depending on the pre-reform eligibility for paid parental leave and the amount of benefit payments after the reform.

Source: Own compilation. 
Table 3: Descriptive statistics

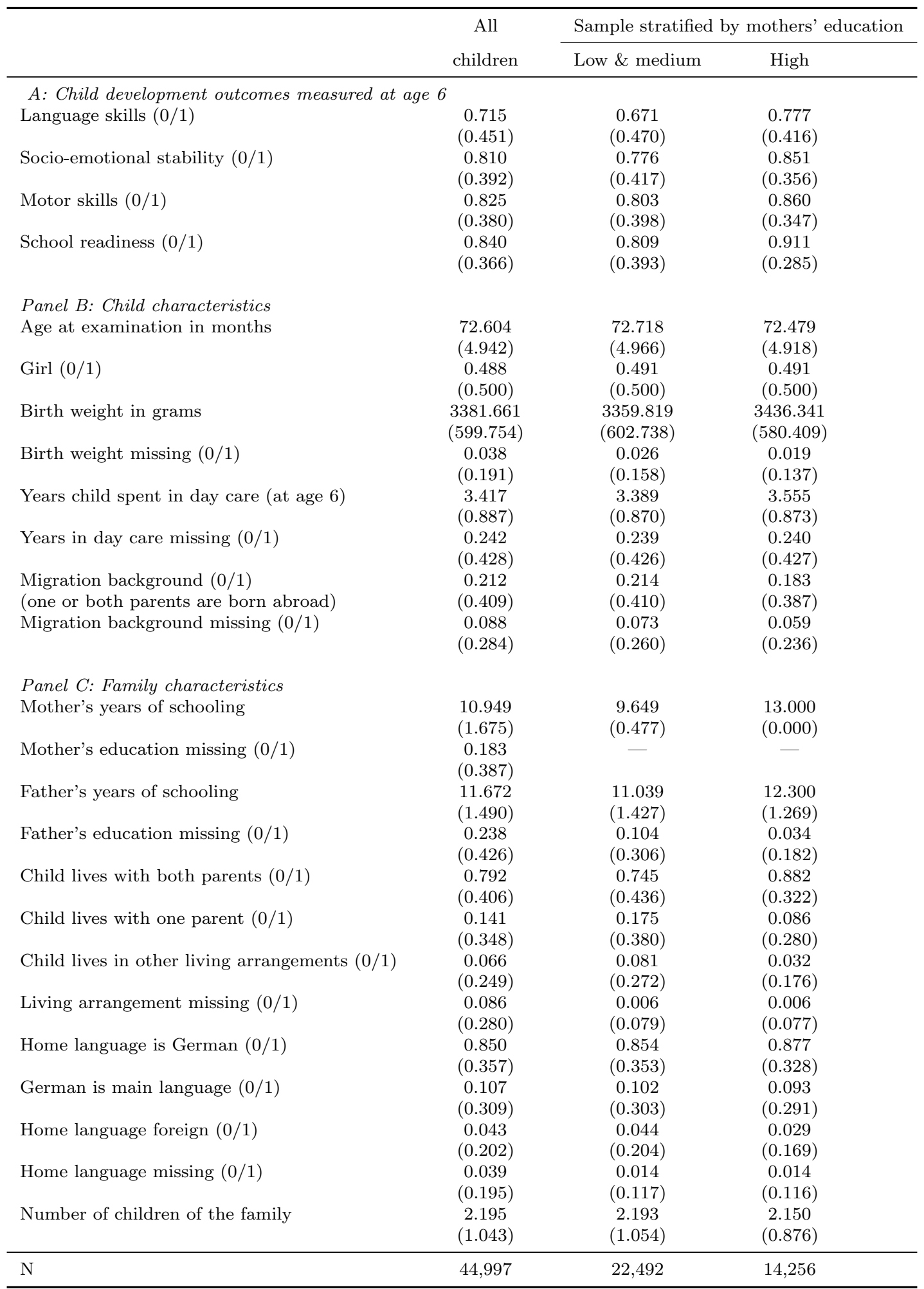

Notes: This table reports descriptive statistics for our main samples. "Low \& medium" education refers to lower and medium-secondary school certificates. "High" education refers to upper-secondary school certificates (Abitur). Standard deviations are reported in parentheses. The means have been calculated based on non-missing information.

Source: Own calculations based on school entrance examinations for Schleswig-Holstein for children born between July 2005 and June 2008. 
Table 4: The relation between child development outcomes and child and family characteristics

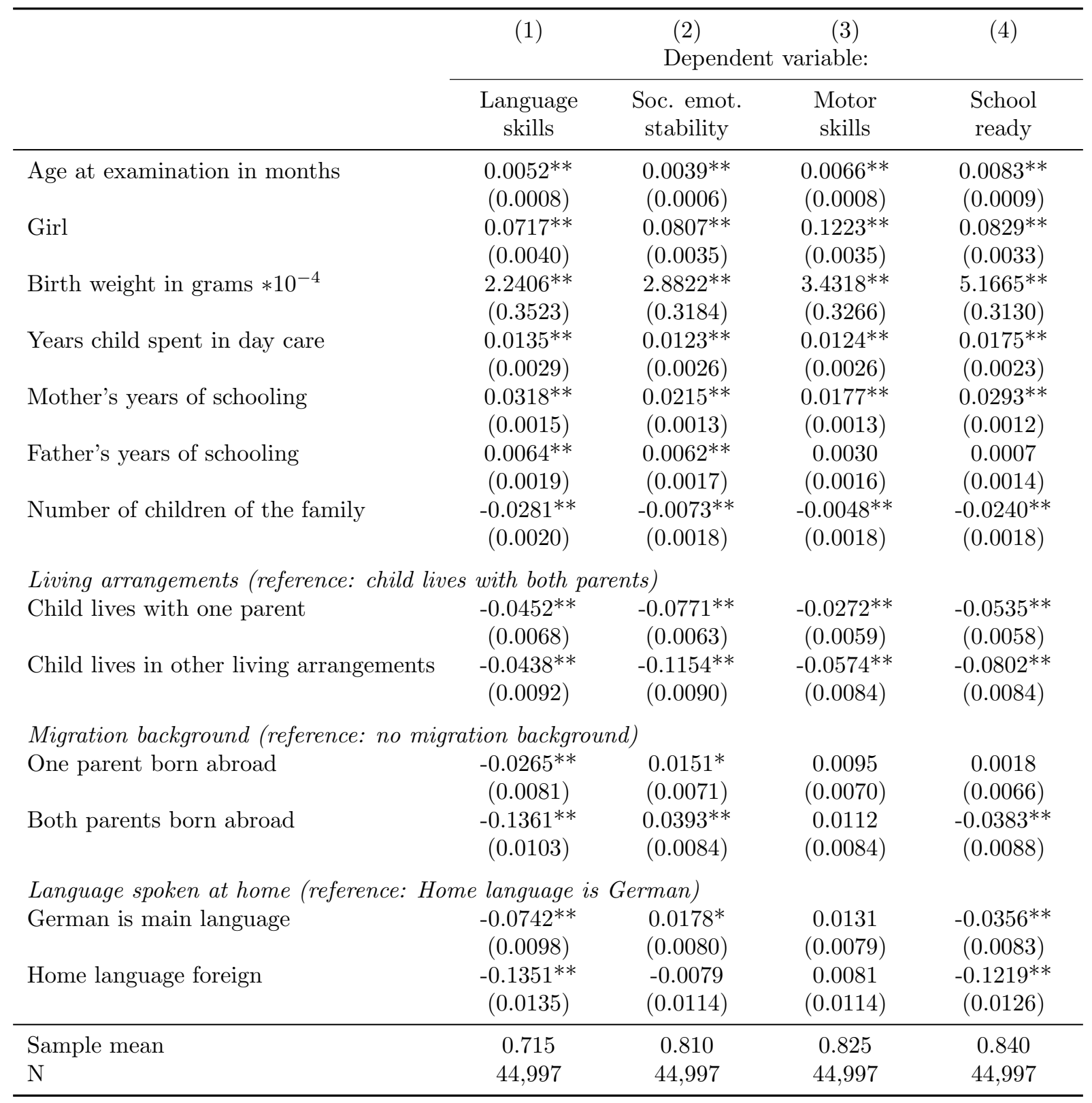

Notes: This table reports multivariate OLS regression results of the child development outcome (column) on the variables listed in the rows. These regressions include the following control variables: examination year-by-county fixed effects, birth months fixed effects and birth cohort fixed effects and dummies for missing variables. Missing values are imputed (zero-category for dummy variables and sample means for continuous variables). Robust standard errors are reported in parentheses. ${ }^{* *} p<0.01,{ }^{*} p<0.05$.

Source: Own calculations based on school entrance examinations for Schleswig-Holstein for children born between July 2005 and June 2008. 


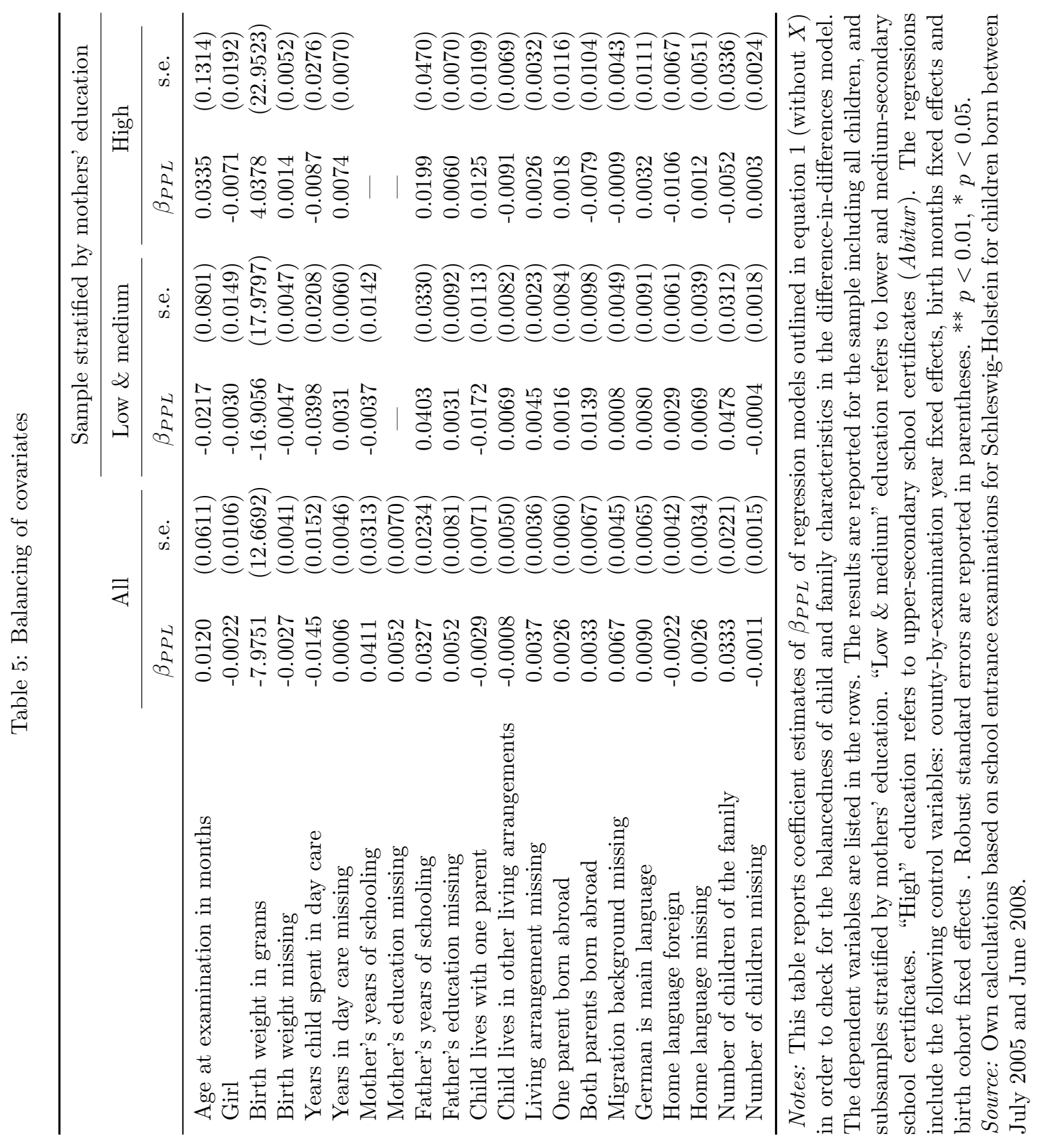




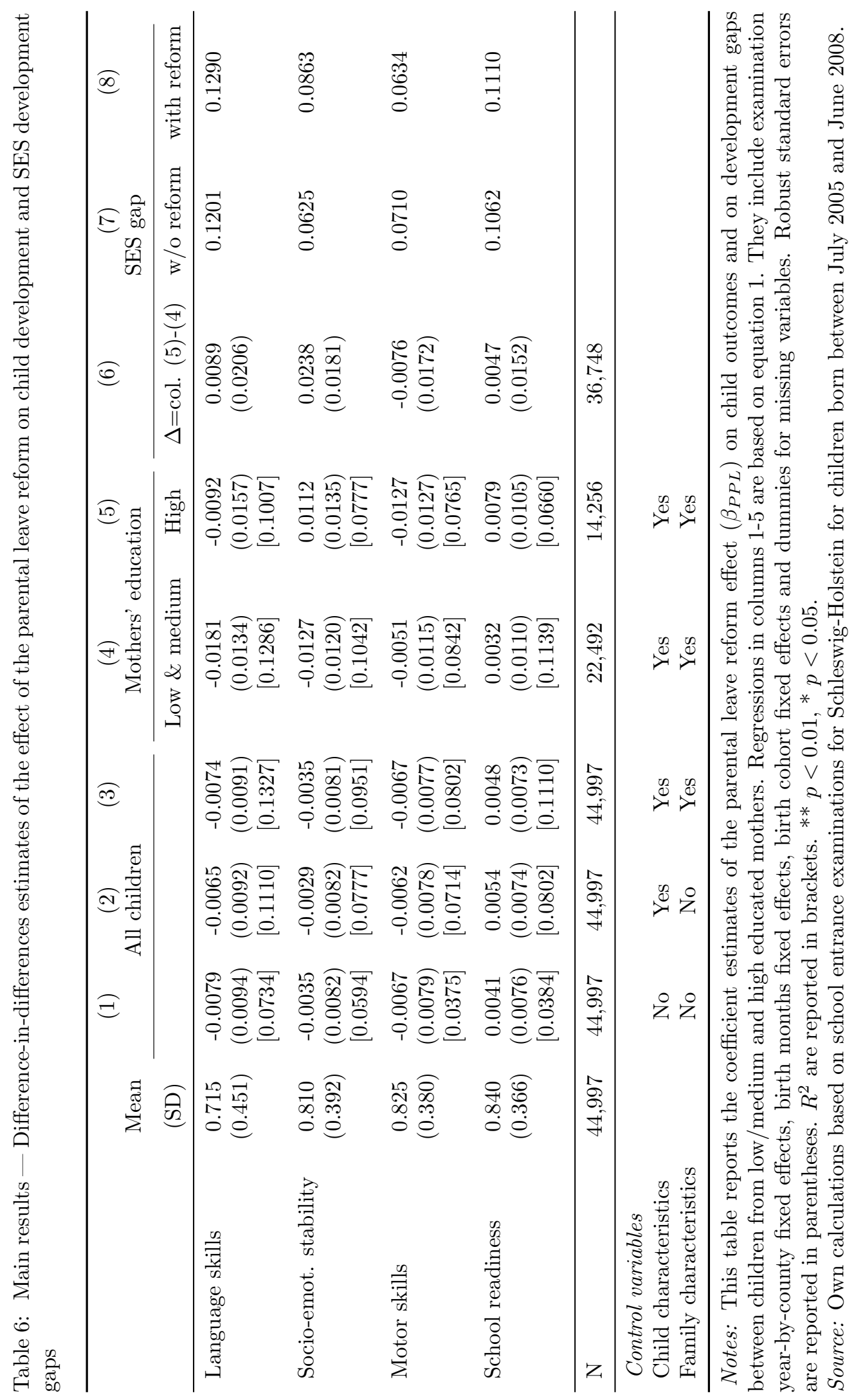


Table 7: Heterogeneity analysis by gender and parental education

\begin{tabular}{|c|c|c|c|c|c|c|c|}
\hline & \multirow{2}{*}{$\begin{array}{l}\text { (1) } \\
\text { All }\end{array}$} & \multicolumn{2}{|c|}{$\begin{array}{l}\text { (2) } \\
\text { Mothers' } \\
\text { education }\end{array}$} & \multicolumn{2}{|c|}{$\begin{array}{l}\text { Fathers' } \\
\text { education }\end{array}$} & \multicolumn{2}{|c|}{$\begin{array}{l}\text { Highest household } \\
\text { education }\end{array}$} \\
\hline & & Low/med. & High & Low/med. & High & Low/med. & High \\
\hline Girls: Language skills & $\begin{array}{c}0.0069 \\
(0.0128)\end{array}$ & $\begin{array}{l}-0.0093 \\
(0.0189)\end{array}$ & $\begin{array}{c}0.0071 \\
(0.0216)\end{array}$ & $\begin{array}{c}0.0064 \\
(0.0199)\end{array}$ & $\begin{array}{l}-0.0152 \\
(0.0217)\end{array}$ & $\begin{array}{l}-0.0094 \\
(0.0229)\end{array}$ & $\begin{array}{c}0.0026 \\
(0.0193)\end{array}$ \\
\hline Boys: Language skills & $\begin{array}{c}-0.0202 \\
(0.0130)\end{array}$ & $\begin{array}{l}-0.0253 \\
(0.0190)\end{array}$ & $\begin{array}{l}-0.0255 \\
(0.0226)\end{array}$ & $\begin{array}{l}-0.0272 \\
(0.0201)\end{array}$ & $\begin{array}{c}-0.0120 \\
(0.0226)\end{array}$ & $\begin{array}{l}-0.0196 \\
(0.0228)\end{array}$ & $\begin{array}{c}-0.0256 \\
(0.0201)\end{array}$ \\
\hline Girls: Socio-emo. stability & $\begin{array}{c}-0.0142 \\
(0.0109)\end{array}$ & $\begin{array}{l}-0.0306 \\
(0.0163)\end{array}$ & $\begin{array}{c}0.0069 \\
(0.0179)\end{array}$ & $\begin{array}{l}-0.0223 \\
(0.0170)\end{array}$ & $\begin{array}{l}-0.0174 \\
(0.0176)\end{array}$ & $\begin{array}{c}-0.0391 * \\
(0.0194)\end{array}$ & $\begin{array}{c}-0.0017 \\
(0.0160)\end{array}$ \\
\hline Boys: Socio-emo. stability & $\begin{array}{c}0.0053 \\
(0.0119)\end{array}$ & $\begin{array}{c}0.0028 \\
(0.0175)\end{array}$ & $\begin{array}{c}0.0132 \\
(0.0200)\end{array}$ & $\begin{array}{c}0.0012 \\
(0.0186)\end{array}$ & $\begin{array}{c}0.0254 \\
(0.0196)\end{array}$ & $\begin{array}{l}-0.0011 \\
(0.0211)\end{array}$ & $\begin{array}{c}0.0217 \\
(0.0178)\end{array}$ \\
\hline Girls: Motor skills & $\begin{array}{c}-0.0038 \\
(0.0095)\end{array}$ & $\begin{array}{c}0.0007 \\
(0.0144)\end{array}$ & $\begin{array}{c}0.0007 \\
(0.0146)\end{array}$ & $\begin{array}{c}0.0029 \\
(0.0146)\end{array}$ & $\begin{array}{l}-0.0068 \\
(0.0155)\end{array}$ & $\begin{array}{c}0.0003 \\
(0.0170)\end{array}$ & $\begin{array}{l}-0.0030 \\
(0.0135)\end{array}$ \\
\hline Boys: Motor skills & $\begin{array}{c}-0.0103 \\
(0.0120)\end{array}$ & $\begin{array}{l}-0.0115 \\
(0.0176)\end{array}$ & $\begin{array}{c}-0.0271 \\
(0.0202)\end{array}$ & $\begin{array}{c}-0.0195 \\
(0.0187)\end{array}$ & $\begin{array}{c}-0.0144 \\
(0.0202)\end{array}$ & $\begin{array}{c}-0.0139 \\
(0.0213)\end{array}$ & $\begin{array}{c}-0.0269 \\
(0.0180)\end{array}$ \\
\hline Girls: School readiness & $\begin{array}{c}0.0009 \\
(0.0094)\end{array}$ & $\begin{array}{l}-0.0079 \\
(0.0143)\end{array}$ & $\begin{array}{c}0.0145 \\
(0.0124)\end{array}$ & $\begin{array}{l}-0.0038 \\
(0.0145)\end{array}$ & $\begin{array}{c}0.0034 \\
(0.0130)\end{array}$ & $\begin{array}{l}-0.0072 \\
(0.0171)\end{array}$ & $\begin{array}{c}0.0052 \\
(0.0114)\end{array}$ \\
\hline Boys: School readiness & $\begin{array}{c}0.0076 \\
(0.0110)\end{array}$ & $\begin{array}{c}0.0114 \\
(0.0166)\end{array}$ & $\begin{array}{c}0.0013 \\
(0.0166)\end{array}$ & $\begin{array}{l}-0.0003 \\
(0.0172)\end{array}$ & $\begin{array}{c}0.0160 \\
(0.0170)\end{array}$ & $\begin{array}{c}0.0120 \\
(0.0200)\end{array}$ & $\begin{array}{c}-0.0002 \\
(0.0151)\end{array}$ \\
\hline Number of girls & 21,981 & 11,033 & 6,994 & 9,875 & 6,929 & 7,759 & 8,867 \\
\hline Number of boys & 23,016 & 11,459 & 7,262 & 10,188 & 7,278 & 8,039 & 9,248 \\
\hline
\end{tabular}

Notes: This table reports the estimation results of the parental leave reform on child outcomes on samples stratified by gender and different definitions of parental education. Each coefficient comes from a separate regression. All regressions include examination year-by-county fixed effects, birth months fixed effects, birth cohort fixed effects, dummies for missing variables and control variables for child and family characteristics. Robust standard errors are reported in parentheses. ${ }^{* *} p<0.01,{ }^{*} p<0.05$.

Source: Own calculations based on school entrance examinations for Schleswig-Holstein for children born between July 2005 and June 2008. 


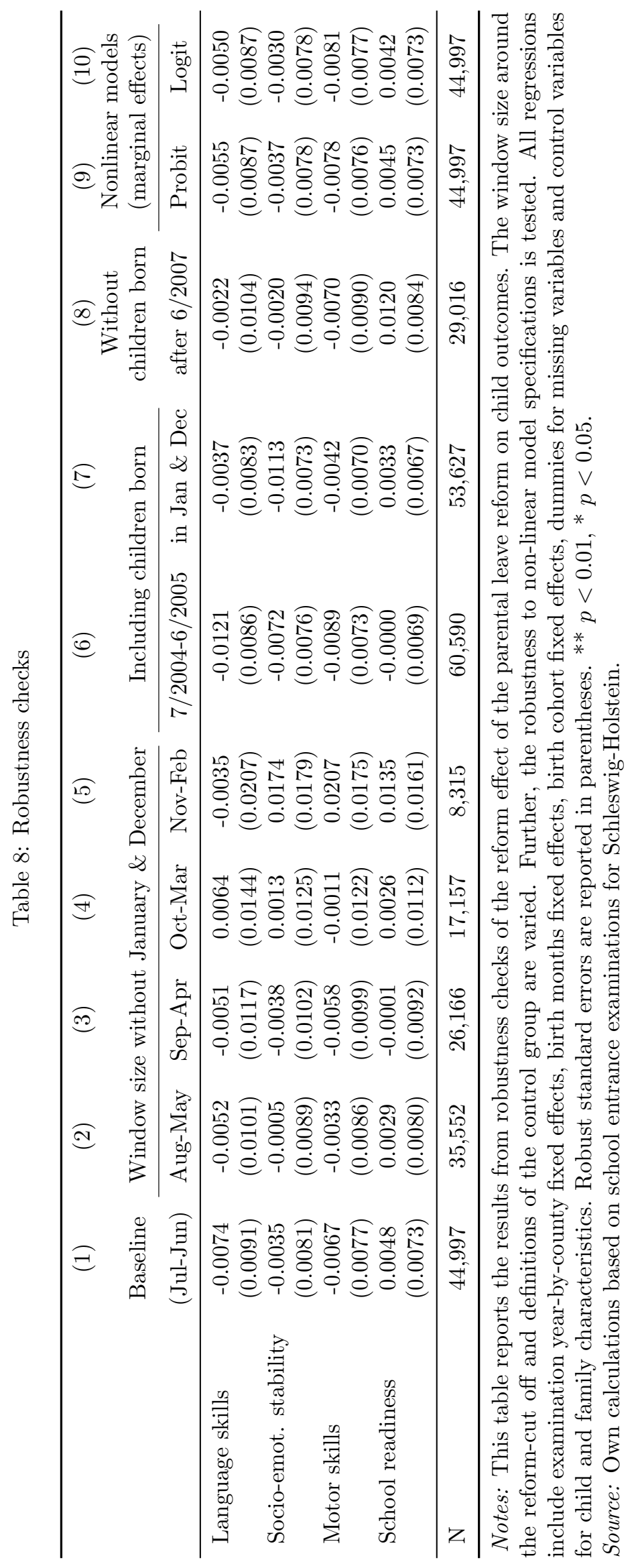


Table 9: Common trend checks

\begin{tabular}{|c|c|c|c|c|c|c|}
\hline & \multirow{3}{*}{$\begin{array}{c}\text { (1) } \\
\text { Baseline }\end{array}$} & \multirow{2}{*}{\multicolumn{2}{|c|}{$\begin{array}{l}(2) \\
\text { Cohort-specific } \\
\text { time trends }\end{array}$}} & (4) & (5) & (6) \\
\hline & & & & \multicolumn{2}{|c|}{ Placebo reforms } & \multirow{2}{*}{$\begin{array}{l}\text { Regression } \\
\text { discontinuity }\end{array}$} \\
\hline & & Linear & Quadratic & 1 year earlier & Mar/Apr 2007 & \\
\hline Language skills & $\begin{array}{c}-0.0074 \\
(0.0091)\end{array}$ & $\begin{array}{c}0.0092 \\
(0.0239)\end{array}$ & $\begin{array}{c}0.0090 \\
(0.0239)\end{array}$ & $\begin{array}{c}-0.0095 \\
(0.0099)\end{array}$ & $\begin{array}{c}-0.0069 \\
(0.0131)\end{array}$ & $\begin{array}{l}-0.0145 \\
(0.0202)\end{array}$ \\
\hline Socio-emot. stability & $\begin{array}{l}-0.0035 \\
(0.0081)\end{array}$ & $\begin{array}{c}0.0107 \\
(0.0210)\end{array}$ & $\begin{array}{c}0.0102 \\
(0.0210)\end{array}$ & $\begin{array}{l}-0.0010 \\
(0.0089)\end{array}$ & $\begin{array}{l}-0.0138 \\
(0.0117)\end{array}$ & $\begin{array}{c}0.0005 \\
(0.0176)\end{array}$ \\
\hline Motor skills & $\begin{array}{l}-0.0067 \\
(0.0077)\end{array}$ & $\begin{array}{c}0.0135 \\
(0.0204)\end{array}$ & $\begin{array}{c}0.0132 \\
(0.0204)\end{array}$ & $\begin{array}{c}0.0027 \\
(0.0087)\end{array}$ & $\begin{array}{l}-0.0030 \\
(0.0116)\end{array}$ & $\begin{array}{c}0.0101 \\
(0.0170)\end{array}$ \\
\hline School readiness & $\begin{array}{c}0.0048 \\
(0.0073)\end{array}$ & $\begin{array}{l}-0.0033 \\
(0.0191)\end{array}$ & $\begin{array}{l}-0.0038 \\
(0.0191)\end{array}$ & $\begin{array}{l}-0.0087 \\
(0.0082)\end{array}$ & $\begin{array}{l}-0.0054 \\
(0.0107)\end{array}$ & $\begin{array}{c}0.0070 \\
(0.0159)\end{array}$ \\
\hline $\mathrm{N}$ & 44,997 & 44,997 & 44,997 & 44,997 & 21,540 & 13,998 \\
\hline
\end{tabular}

Notes: This table reports the results of sensitivity checks to alternative model specifications for the common trend assumption. It also reports the results from placebo regressions. All regressions include examination year-by-county fixed effects, birth months fixed effects, birth cohort fixed effects, dummies for missing variables and control variables for child and family characteristics. Robust standard errors are reported in parentheses. ${ }^{* *} p<0.01,{ }^{*} p<0.05$.

Source: Own calculations based on school entrance examinations for Schleswig-Holstein. 


\section{Appendix}

Table A.1: Comparison of socio-economic characteristics of Schleswig-Holstein to the rest of West Germany

\begin{tabular}{|c|c|c|c|}
\hline & Schleswig-Holstein & West & West* \\
\hline Age & 44.07 & 43.21 & 43.22 \\
\hline Female & 0.52 & 0.52 & 0.52 \\
\hline Unmarried & 0.38 & 0.39 & 0.39 \\
\hline Married & 0.47 & 0.47 & 0.48 \\
\hline Divorced & 0.07 & 0.06 & 0.06 \\
\hline Household size & 2.67 & 2.75 & 2.76 \\
\hline Children in household & 0.92 & 0.97 & 0.98 \\
\hline Born in Germany & 0.89 & 0.85 & 0.85 \\
\hline Working & 0.45 & 0.47 & 0.47 \\
\hline Unemployed & 0.03 & 0.03 & 0.03 \\
\hline Out of the labour force & 0.51 & 0.5 & 0.5 \\
\hline Female labour force participation rate & 0.80 & 0.80 & 0.80 \\
\hline \multicolumn{4}{|l|}{ Highest level of education } \\
\hline$\leq$ ISCED3 & 0.25 & 0.28 & 0.28 \\
\hline$\overline{\mathrm{ISCED}} 4$ & 0.04 & 0.05 & 0.05 \\
\hline ISCED5 & 0.47 & 0.42 & 0.42 \\
\hline ISCED6 & 0.06 & 0.06 & 0.06 \\
\hline$\leq \mathrm{ISCED} 7$ & 0.18 & 0.20 & 0.20 \\
\hline \multicolumn{4}{|l|}{ Personal monthly net income } \\
\hline $0-1,100$ & 0.52 & 0.53 & 0.53 \\
\hline $1,100-2,300$ & 0.29 & 0.3 & 0.3 \\
\hline $2,300-3,600$ & 0.07 & 0.06 & 0.06 \\
\hline $3,600-5,000$ & 0.03 & 0.03 & 0.03 \\
\hline $5,000-18,000$ & 0.01 & 0.01 & 0.01 \\
\hline \multicolumn{4}{|l|}{ Household monthly net income } \\
\hline $0-1,100$ & 0.1 & 0.1 & 0.1 \\
\hline $1,100-2,300$ & 0.29 & 0.31 & 0.31 \\
\hline $2,300-3,600$ & 0.19 & 0.2 & 0.2 \\
\hline $3,600-5,000$ & 0.14 & 0.15 & 0.15 \\
\hline $5,000-18,000$ & 0.09 & 0.09 & 0.09 \\
\hline \multicolumn{4}{|l|}{ Municipality size } \\
\hline$<2,000$ & 0.19 & 0.05 & 0.05 \\
\hline $2,000-5,000$ & 0.11 & 0.09 & 0.09 \\
\hline $5,000-10,000$ & 0.12 & 0.12 & 0.12 \\
\hline $10,000-50,000$ & 0.33 & 0.35 & 0.36 \\
\hline $50,000-100,000$ & 0.08 & 0.1 & 0.1 \\
\hline$>100,000$ & 0.16 & 0.31 & 0.27 \\
\hline $\mathrm{N}$ & 25,249 & 533,229 & 513,241 \\
\hline
\end{tabular}

Notes: This table reports socio-economic and socio-demographic characteristics of the population in Schleswig-Holstein and West Germany. "West" includes only West German federal states, without Schleswig-Holstein. "West*" further excludes the city-states of Hamburg and Bremen.

Source: Own calculations based on German Mikrozensus 2009. 
Table A.2: Effects of the parental leave reform on alternative definitions of child development

\begin{tabular}{|c|c|c|c|c|c|c|c|}
\hline \multirow[t]{3}{*}{ Panel A: Language skills } & \multirow{3}{*}{$\begin{array}{l}\text { Language } \\
\text { score, mean } \\
\text { (SD) }\end{array}$} & \multicolumn{6}{|c|}{ Treatment effect on } \\
\hline & & \multirow[b]{2}{*}{$\begin{array}{l}\text { Language } \\
\text { score }\end{array}$} & \multicolumn{5}{|c|}{ language score in plural words, pseudo words \& prepositions } \\
\hline & & & $\begin{array}{l}\leq 12 \\
(5 \%)\end{array}$ & $\begin{array}{c}13-16 \\
(13 \%)\end{array}$ & $\begin{array}{c}17-19 \\
(33 \%)\end{array}$ & $\begin{array}{c}20 \\
(21 \%)\end{array}$ & $\begin{array}{c}21 \\
(28 \%)\end{array}$ \\
\hline $\begin{array}{l}\text { All children } \\
(N=28,001)\end{array}$ & $\begin{array}{c}18.5264 \\
(3.0599)\end{array}$ & $\begin{array}{l}-0.0980 \\
(0.0714)\end{array}$ & $\begin{array}{c}0.0065 \\
(0.0056)\end{array}$ & $\begin{array}{c}0.0129 \\
(0.0086)\end{array}$ & $\begin{array}{l}-0.0032 \\
(0.0122)\end{array}$ & $\begin{array}{l}-0.0039 \\
(0.0106)\end{array}$ & $\begin{array}{l}-0.0124 \\
(0.0110)\end{array}$ \\
\hline $\begin{array}{l}\text { Mothers with low/medium } \\
\text { education }(N=14,890)\end{array}$ & $\begin{array}{l}18.2052 \\
(3.1551)\end{array}$ & $\begin{array}{l}-0.1133 \\
(0.1014)\end{array}$ & $\begin{array}{c}0.0115 \\
(0.0082)\end{array}$ & $\begin{array}{c}0.0181 \\
(0.0126)\end{array}$ & $\begin{array}{l}-0.0238 \\
(0.0168)\end{array}$ & $\begin{array}{l}-0.0086 \\
(0.0141)\end{array}$ & $\begin{array}{c}0.0029 \\
(0.0140)\end{array}$ \\
\hline $\begin{array}{l}\text { Mothers with high } \\
\text { education }(N=8,936)\end{array}$ & $\begin{array}{l}19.4417 \\
(2.3083)\end{array}$ & $\begin{array}{l}-0.0453 \\
(0.0974)\end{array}$ & $\begin{array}{l}-0.0069 \\
(0.0057)\end{array}$ & $\begin{array}{c}0.0080 \\
(0.0115)\end{array}$ & $\begin{array}{c}0.0301 \\
(0.0211)\end{array}$ & $\begin{array}{c}0.0013 \\
(0.0202)\end{array}$ & $\begin{array}{l}-0.0324 \\
(0.0220)\end{array}$ \\
\hline \multirow{3}{*}{$\begin{array}{l}\text { Panel B: Socio-emotional } \\
\text { stability }\end{array}$} & \multirow{3}{*}{$\begin{array}{l}\text { SDQ score, } \\
\text { mean } \\
(\mathrm{SD})\end{array}$} & \multicolumn{6}{|c|}{ Treatment effect on } \\
\hline & & & \multicolumn{5}{|c|}{ specific parts of the SDQ score distribution: Score $=$} \\
\hline & & $\begin{array}{l}\text { SDQ } \\
\text { score }\end{array}$ & $\begin{array}{c}0 \\
(9 \%)\end{array}$ & $\begin{array}{l}1-4 \\
(31 \%)\end{array}$ & $\begin{array}{l}5-8 \\
(32 \%)\end{array}$ & $\begin{array}{l}9-12 \\
(17 \%)\end{array}$ & $\begin{array}{l}\geq 13 \\
(11 \%)\end{array}$ \\
\hline $\begin{array}{l}\text { All children } \\
(N=20,603)\end{array}$ & $\begin{array}{c}6.4232 \\
(4.8933)\end{array}$ & $\begin{array}{c}0.1959 \\
(0.1362)\end{array}$ & $\begin{array}{l}-0.0024 \\
(0.0077)\end{array}$ & $\begin{array}{l}-0.0014 \\
(0.0131)\end{array}$ & $\begin{array}{l}-0.0249 \\
(0.0139)\end{array}$ & $\begin{array}{c}0.0189 \\
(0.0110)\end{array}$ & $\begin{array}{l}0.0098 \\
(0.0091)\end{array}$ \\
\hline $\begin{array}{l}\text { Mothers with low/medium } \\
\text { education }(N=11,371)\end{array}$ & $\begin{array}{c}7.2702 \\
(4.9947)\end{array}$ & $\begin{array}{c}0.0895 \\
(0.1870)\end{array}$ & $\begin{array}{c}0.0006 \\
(0.0088)\end{array}$ & $\begin{array}{l}-0.0126 \\
(0.0168)\end{array}$ & $\begin{array}{l}-0.0039 \\
(0.0187)\end{array}$ & $\begin{array}{c}0.0200 \\
(0.0159)\end{array}$ & $\begin{array}{l}-0.0041 \\
(0.0135)\end{array}$ \\
\hline $\begin{array}{l}\text { Mothers with high } \\
\text { education }(N=7,042)\end{array}$ & $\begin{array}{c}5.0849 \\
(4.1355)\end{array}$ & $\begin{array}{c}0.3692 \\
(0.2083)\end{array}$ & $\begin{array}{l}-0.0078 \\
(0.0149)\end{array}$ & $\begin{array}{l}-0.0033 \\
(0.0249)\end{array}$ & $\begin{array}{l}-0.0352 \\
(0.0241)\end{array}$ & $\begin{array}{c}0.0233 \\
(0.0165)\end{array}$ & $\begin{array}{c}0.0230 \\
(0.0120)\end{array}$ \\
\hline \multirow[t]{3}{*}{ Panel C: Motor skills } & \multirow{3}{*}{$\begin{array}{l}\text { Jumps, } \\
\text { mean } \\
\text { (SD) }\end{array}$} & \multicolumn{6}{|c|}{ Treatment effect on } \\
\hline & & & \multicolumn{5}{|c|}{ side-jumps within 10 seconds } \\
\hline & & $\begin{array}{l}\text { No. of } \\
\text { side-jumps }\end{array}$ & $\begin{array}{l}\leq 7 \\
(13 \%)\end{array}$ & $\begin{array}{l}8-9 \\
(28 \%)\end{array}$ & $\begin{array}{c}10 \\
(31 \%, \text { mode })\end{array}$ & $\begin{array}{c}11-13 \\
(18 \%)\end{array}$ & $\begin{array}{l}\geq 14 \\
(10 \%)\end{array}$ \\
\hline $\begin{array}{l}\text { All children } \\
(N=20,321)\end{array}$ & $\begin{array}{l}10.0705 \\
(3.0472)\end{array}$ & $\begin{array}{l}-0.1211 \\
(0.0858)\end{array}$ & $\begin{array}{c}0.0119 \\
(0.0099)\end{array}$ & $\begin{array}{c}0.0092 \\
(0.0134)\end{array}$ & $\begin{array}{l}-0.0184 \\
(0.0134)\end{array}$ & $\begin{array}{c}0.0100 \\
(0.0116)\end{array}$ & $\begin{array}{l}-0.0127 \\
(0.0088)\end{array}$ \\
\hline $\begin{array}{l}\text { Mothers with low/medium } \\
\text { education }(N=11,126)\end{array}$ & $\begin{array}{c}9.9229 \\
(3.0253)\end{array}$ & $\begin{array}{l}-0.0516 \\
(0.1138)\end{array}$ & $\begin{array}{c}0.0003 \\
(0.0139)\end{array}$ & $\begin{array}{c}0.0245 \\
(0.0183)\end{array}$ & $\begin{array}{l}-0.0203 \\
(0.0179)\end{array}$ & $\begin{array}{c}0.0003 \\
(0.0154)\end{array}$ & $\begin{array}{l}-0.0048 \\
(0.0114)\end{array}$ \\
\hline $\begin{array}{l}\text { Mothers with high } \\
\text { education }(N=6,947)\end{array}$ & $\begin{array}{l}10.4814 \\
(3.0984)\end{array}$ & $\begin{array}{l}-0.2016 \\
(0.1585)\end{array}$ & $\begin{array}{c}0.0060 \\
(0.0150)\end{array}$ & $\begin{array}{c}0.0114 \\
(0.0221)\end{array}$ & $\begin{array}{l}-0.0248 \\
(0.0237)\end{array}$ & $\begin{array}{c}0.0402 \\
(0.0210)\end{array}$ & $\begin{array}{l}-0.0328 \\
(0.0172)\end{array}$ \\
\hline
\end{tabular}

Notes: This table reports estimated reform effects on subdimensions tested in school entrance examinations, i.e. on SOPESS language test scores (plurals, pseudo words and prepositions, see Panel A), on the sum of SDQ subscales, ranging from 0 to 40 (Panel B), and on side-jumps (Panel C). The treatment effects are reported for the pooled sample, and for subsamples stratified by mothers' education. All regressions are based on model 1, and include examination year-by-county fixed effects, birth months fixed effects, birth cohort fixed effects, dummies for missing variables and control variables for child and family characteristics. The sample is restricted to counties that delivered the raw scores to the data compiling Ministry of Social Affairs, Health, Family and Equal Opportunities in Schleswig-Holstein. Robust standard errors are reported in parentheses. ${ }^{* *} p<0.01, * p<0.05$.

Source: Own calculations based on school entrance examinations for Schleswig-Holstein. 
Table A.3: Balancing of covariates for varying window sizes around the reform cutoff

\begin{tabular}{|c|c|c|c|c|}
\hline & $(1)$ & (2) & (3) & (4) \\
\hline & \multicolumn{4}{|c|}{ Window size without January \& December } \\
\hline & Nov-Feb & Oct-Mar & Sep-Apr & Aug-May \\
\hline \multirow[t]{2}{*}{ Age at examination in months } & 0.0062 & -0.0140 & 0.0105 & -0.0013 \\
\hline & $(0.1280)$ & $(0.1062)$ & $(0.0817)$ & $(0.0693)$ \\
\hline \multirow[t]{2}{*}{ Girl } & 0.0062 & -0.0042 & 0.0105 & 0.0030 \\
\hline & $(0.0240)$ & $(0.0166)$ & $(0.0136)$ & $(0.0117)$ \\
\hline \multirow[t]{2}{*}{ Birth weight in grams } & -35.0317 & 0.8321 & -8.8259 & -12.8237 \\
\hline & $(28.3773)$ & $(19.8000)$ & $(16.1827)$ & $(14.1342)$ \\
\hline \multirow[t]{2}{*}{ Years child spent in day care } & 0.0145 & -0.0076 & -0.0149 & -0.0179 \\
\hline & $(0.0344)$ & $(0.0240)$ & $(0.0194)$ & $(0.0167)$ \\
\hline \multirow{2}{*}{ Mother's years of schooling } & 0.0752 & 0.0379 & 0.0077 & 0.0216 \\
\hline & $(0.0704)$ & $(0.0493)$ & $(0.0403)$ & $(0.0348)$ \\
\hline \multirow{2}{*}{ Father's years of schooling } & -0.0076 & 0.0181 & 0.0307 & 0.0174 \\
\hline & $(0.0529)$ & $(0.0369)$ & $(0.0301)$ & $(0.0261)$ \\
\hline \multirow[t]{2}{*}{ Child lives with both parents } & 0.0127 & -0.0127 & -0.0013 & -0.0059 \\
\hline & $(0.0195)$ & $(0.0136)$ & $(0.0111)$ & $(0.0096)$ \\
\hline \multirow[t]{2}{*}{ Child lives with one parent } & -0.0004 & 0.0120 & -0.0001 & 0.0046 \\
\hline & $(0.0160)$ & $(0.0110)$ & $(0.0091)$ & $(0.0079)$ \\
\hline \multirow[t]{2}{*}{ Child lives in other living arrangements } & -0.0086 & -0.0015 & -0.0009 & -0.0014 \\
\hline & $(0.0114)$ & $(0.0080)$ & $(0.0064)$ & $(0.0056)$ \\
\hline \multirow[t]{2}{*}{ At least one parent with mig. back. } & 0.0199 & 0.0076 & 0.0110 & 0.0125 \\
\hline & $(0.0199)$ & $(0.0140)$ & $(0.0115)$ & $(0.0099)$ \\
\hline \multirow[t]{2}{*}{ German is main language } & -0.0219 & -0.0123 & -0.0178 & -0.0141 \\
\hline & $(0.0176)$ & $(0.0124)$ & $(0.0101)$ & $(0.0088)$ \\
\hline \multirow[t]{2}{*}{ Home language foreign } & 0.0085 & 0.0035 & 0.0004 & -0.0029 \\
\hline & $(0.0095)$ & $(0.0067)$ & $(0.0054)$ & $(0.0047)$ \\
\hline \multirow{2}{*}{ Number of children of the family } & $0.1110^{*}$ & $0.0724^{*}$ & 0.0515 & 0.0328 \\
\hline & $(0.0508)$ & $(0.0348)$ & $(0.0282)$ & $(0.0245)$ \\
\hline $\mathrm{N}$ & 8,315 & 17,157 & 26,166 & 35,552 \\
\hline
\end{tabular}

Notes: This table reports results of difference-in-differences regressions as outlined in equation 1 on the covariates listed in the rows with varying window sizes around the reform cutoff. The regressions include the following control variables: examination year-by-county fixed effects, birth months fixed effects and birth cohort fixed effects. The regressions exclude the X-vector. Each coefficient estimates stems from a separate regression. Robust standard errors are reported in parentheses. ${ }^{* *} p<0.01,{ }^{*} p<0.05$.

Source: Own calculations based on school entrance examinations for Schleswig-Holstein. 


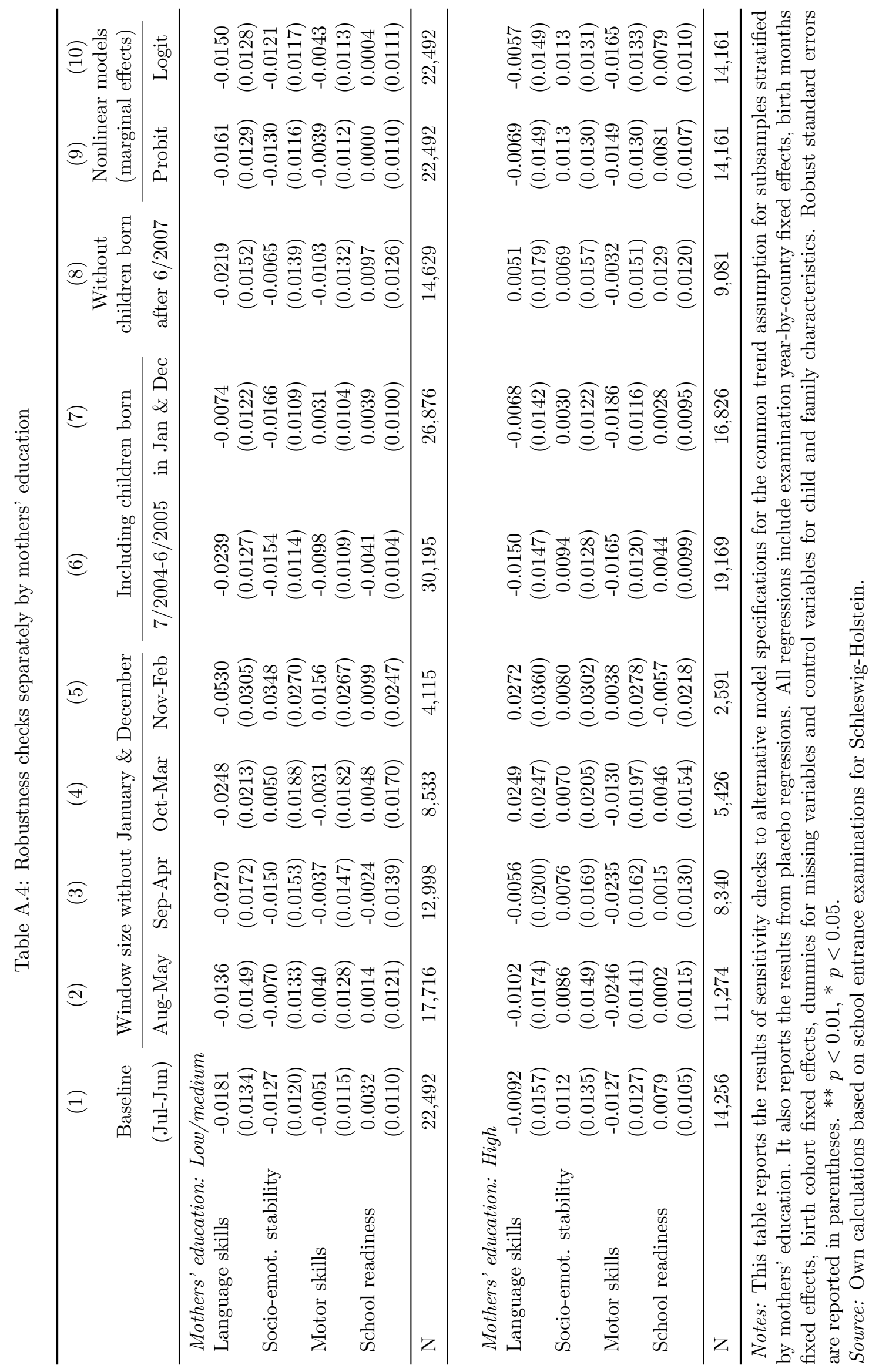


Table A.5: Results for pooled child outcomes - Difference-in-differences estimates of the effect of the parental leave reform on child development

\begin{tabular}{|c|c|c|c|c|c|}
\hline & \multirow[t]{2}{*}{ (1) } & \multirow[t]{2}{*}{$\begin{array}{c}(2) \\
\text { All children }\end{array}$} & \multirow[t]{2}{*}{ (3) } & \multicolumn{2}{|c|}{$\begin{array}{c}(4) \quad(5) \\
\text { Mothers' education }\end{array}$} \\
\hline & & & & Low/medium & High \\
\hline \multicolumn{6}{|c|}{ Pooling language skills, motor skills, socio-emotional stability, and school readiness } \\
\hline \multirow[t]{3}{*}{ Child development } & -0.0035 & -0.0026 & -0.0032 & -0.0082 & -0.0007 \\
\hline & $(0.0055)$ & $(0.0053)$ & $(0.0052)$ & $(0.0078)$ & $(0.0082)$ \\
\hline & {$[0.0468]$} & {$[0.0708]$} & {$[0.0891]$} & {$[0.0922]$} & {$[0.0715]$} \\
\hline $\mathrm{N}$ & 179,988 & 179,988 & 179,988 & 89,968 & 57,024 \\
\hline \multicolumn{6}{|c|}{ Pooling language skills, motor skills, and socio-emotional stability } \\
\hline \multirow[t]{3}{*}{ Child development } & -0.0060 & -0.0052 & -0.0058 & -0.0119 & -0.0036 \\
\hline & $(0.0058)$ & $(0.0056)$ & $(0.0055)$ & $(0.0082)$ & $(0.0091)$ \\
\hline & {$[0.0583]$} & {$[0.0789]$} & {$[0.0943]$} & {$[0.0986]$} & {$[0.0752]$} \\
\hline $\mathrm{N}$ & 134,991 & 134,991 & 134,991 & 67,476 & 42,768 \\
\hline \multicolumn{6}{|l|}{ Control variables } \\
\hline Child characteristics & No & Yes & Yes & Yes & Yes \\
\hline Family characteristics & No & No & Yes & Yes & Yes \\
\hline
\end{tabular}

Notes: This table reports the estimation results of the parental leave reform on child development under the assumption of an equal impact of the reform on all pooled development outcomes. All regressions are based on equation 1. They include examination year-by-county fixed effects, birth months fixed effects, birth cohort fixed effects, dummies for missing variables, and a dummy indicating the different child outcomes. Standard errors are clustered at the child level (44,997 clusters in columns 1-3, 22,492 clusters in column 4, 14,256 clusters in column 5) and reported in parentheses. $R^{2}$ are reported in brackets. ${ }^{* *} p<0.01,{ }^{*} p<0.05$.

Source: Own calculations based on school entrance examinations for Schleswig-Holstein for children born between July 2005 and June 2008. 
Table A.6: Common trend checks separately by mothers' education

\begin{tabular}{|c|c|c|c|c|c|c|}
\hline & \multirow{3}{*}{$\begin{array}{c}\text { (1) } \\
\text { Baseline }\end{array}$} & \multirow{2}{*}{\multicolumn{2}{|c|}{$\begin{array}{l}(2) \\
\text { Cohort-specific } \\
\text { time trends }\end{array}$}} & \multirow{2}{*}{\multicolumn{2}{|c|}{ Placebo reforms }} & \multirow{3}{*}{$\begin{array}{c}(6) \\
\text { Regression } \\
\text { discontinuity }\end{array}$} \\
\hline & & & & & & \\
\hline & & Linear & Quadratic & 1 year earlier & Mar/Apr 2007 & \\
\hline \multicolumn{7}{|c|}{ Mothers' education: Low/medium } \\
\hline Language skills & $\begin{array}{l}-0.0181 \\
(0.0134)\end{array}$ & $\begin{array}{l}-0.0431 \\
(0.0355)\end{array}$ & $\begin{array}{l}-0.0436 \\
(0.0355)\end{array}$ & $\begin{array}{c}0.0093 \\
(0.0145)\end{array}$ & $\begin{array}{c}0.0168 \\
(0.0195)\end{array}$ & $\begin{array}{l}-0.0379 \\
(0.0301)\end{array}$ \\
\hline Socio-emot. stability & $\begin{array}{l}-0.0127 \\
(0.0120)\end{array}$ & $\begin{array}{c}0.0122 \\
(0.0316)\end{array}$ & $\begin{array}{c}0.0126 \\
(0.0316)\end{array}$ & $\begin{array}{l}-0.0105 \\
(0.0132)\end{array}$ & $\begin{array}{l}-0.0165 \\
(0.0176)\end{array}$ & $\begin{array}{c}0.0046 \\
(0.0265)\end{array}$ \\
\hline Motor skills & $\begin{array}{c}-0.0051 \\
(0.0115)\end{array}$ & $\begin{array}{c}0.0194 \\
(0.0307)\end{array}$ & $\begin{array}{c}0.0199 \\
(0.0308)\end{array}$ & $\begin{array}{c}0.0114 \\
(0.0126)\end{array}$ & $\begin{array}{c}-0.0044 \\
(0.0173)\end{array}$ & $\begin{array}{c}0.0150 \\
(0.0259)\end{array}$ \\
\hline School readiness & $\begin{array}{c}0.0032 \\
(0.0110)\end{array}$ & $\begin{array}{l}-0.0076 \\
(0.0291)\end{array}$ & $\begin{array}{l}-0.0070 \\
(0.0291)\end{array}$ & $\begin{array}{l}-0.0088 \\
(0.0123)\end{array}$ & $\begin{array}{l}-0.0100 \\
(0.0163)\end{array}$ & $\begin{array}{c}0.0016 \\
(0.0241)\end{array}$ \\
\hline $\mathrm{N}$ & 22,492 & 22,492 & 22,492 & 22,492 & 10,706 & 6,877 \\
\hline \multicolumn{7}{|c|}{ Mothers' education: High } \\
\hline Language skills & $\begin{array}{c}-0.0092 \\
(0.0157)\end{array}$ & $\begin{array}{c}0.0325 \\
(0.0406)\end{array}$ & $\begin{array}{c}0.0338 \\
(0.0405)\end{array}$ & $\begin{array}{c}-0.0254 \\
(0.0168)\end{array}$ & $\begin{array}{c}-0.0122 \\
(0.0225)\end{array}$ & $\begin{array}{c}-0.0245 \\
(0.0345)\end{array}$ \\
\hline Socio-emot. stability & $\begin{array}{c}0.0112 \\
(0.0135)\end{array}$ & $\begin{array}{c}0.0031 \\
(0.0346)\end{array}$ & $\begin{array}{c}0.0017 \\
(0.0345)\end{array}$ & $\begin{array}{c}0.0108 \\
(0.0147)\end{array}$ & $\begin{array}{c}-0.0134 \\
(0.0190)\end{array}$ & $\begin{array}{l}-0.0030 \\
(0.0292)\end{array}$ \\
\hline Motor skills & $\begin{array}{l}-0.0127 \\
(0.0127)\end{array}$ & $\begin{array}{c}-0.0201 \\
(0.0329)\end{array}$ & $\begin{array}{c}-0.0200 \\
(0.0328)\end{array}$ & $\begin{array}{c}-0.0129 \\
(0.0144)\end{array}$ & $\begin{array}{c}0.0216 \\
(0.0191)\end{array}$ & $\begin{array}{c}-0.0202 \\
(0.0276)\end{array}$ \\
\hline School readiness & $\begin{array}{c}0.0079 \\
(0.0105) \\
\end{array}$ & $\begin{array}{c}-0.0048 \\
(0.0267) \\
\end{array}$ & $\begin{array}{c}-0.0064 \\
(0.0266) \\
\end{array}$ & $\begin{array}{c}-0.0048 \\
(0.0116) \\
\end{array}$ & $\begin{array}{c}-0.0055 \\
(0.0153) \\
\end{array}$ & $\begin{array}{c}0.0150 \\
(0.0223) \\
\end{array}$ \\
\hline $\mathrm{N}$ & 14,256 & 14,256 & 14,256 & 14,256 & 6,910 & 4,426 \\
\hline
\end{tabular}

Notes: This table reports the results of sensitivity checks to alternative model specifications for the common trend assumption for subsamples stratified by mothers' education. It also reports the results from placebo regressions. All regressions include examination year-by-county fixed effects, birth months fixed effects, birth cohort fixed effects, dummies for missing variables and control variables for child and family characteristics. Robust standard errors are reported in parentheses. ${ }^{* *} p<0.01,{ }^{*} p<0.05$.

Source: Own calculations based on school entrance examinations for Schleswig-Holstein. 